\title{
Synchrotron scanning reveals the palaeoneurology of the head-butting Moschops capensis (Therapsida, Dinocephalia)
}

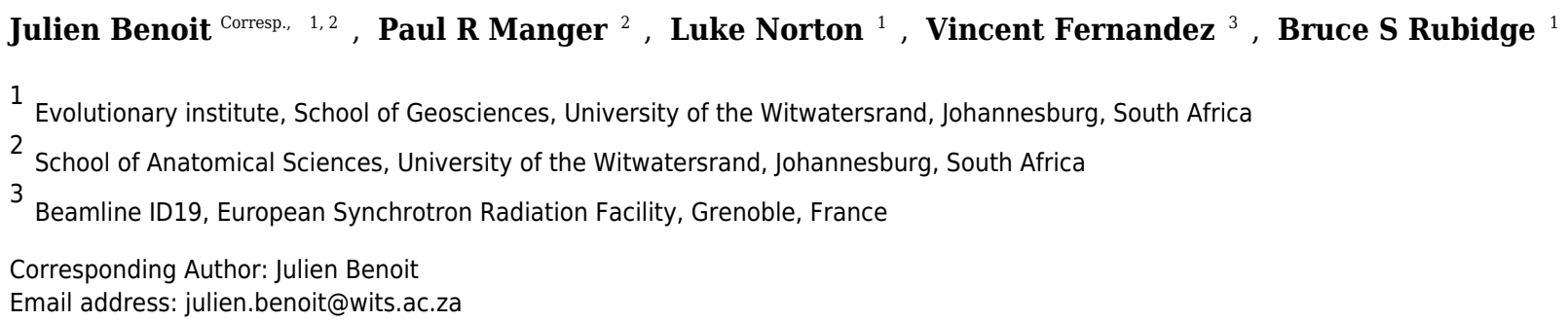

Dinocephalian therapsids are renowned for their massive, pachyostotic and ornamented skulls adapted for head-to-head fighting during intraspecific combat. Synchrotron scanning of the tapinocephalid Moschops capensis reveals, for the first time, numerous anatomical adaptations of the central nervous system related to this combative behaviour. Many neural structures (such as the brain, inner ear and ophthalmic branch of the trigeminal nerve) were completely enclosed and protected by bones, which is unusual for nonmammaliaform therapsids. The nearly complete ossification of the braincase enables precise determination of the brain cavity volume and encephalization quotient, which appears greater than expected for such a large and early herbivore. The practice of head butting is often associated with complex social behaviours and gregariousness in extant species, which are known to influence brain size evolution. Additionally, the plane of the lateral (horizontal) semicircular canal of the bony labyrinth is oriented nearly vertically if the skull is held horizontally, which suggests that the natural position of the head was inclined about $60-65^{\circ}$ to the horizontal. This is consistent with the fighting position inferred from osteology, as well as ground-level browsing. Finally, the unusually large parietal tube may have been filled with thick conjunctive tissue to protect the delicate pineal eye from injury sustained during head butting. 
1 Research Article

2 Title: Synchrotron scanning reveals the palaeoneurology of the head-butting Moschops capensis

3 (Therapsida, Dinocephalia)

4 Authors:

5 Julien Benoit ${ }^{1,2 *}$, Paul R. Manger ${ }^{2}$, Luke A. Norton ${ }^{1}$, Vincent Fernandez ${ }^{3}$, Bruce S. Rubidge ${ }^{1}$

$6{ }^{1}$ Evolutionary Studies Institute (ESI), School of Geosciences, University of the Witwatersrand, 7 PO Wits, 2050, Johannesburg, South Africa

$8{ }^{2}$ School of Anatomical Sciences, University of the Witwatersrand, 7 York Road, Parktown, 9 2193, Johannesburg, South Africa

$10{ }^{3}$ European Synchrotron Radiation Facility, Beamline ID19, 71 rue des Martyrs, 38000 Grenoble, 11 France

$12 *$ Corresponding Author: Julien Benoit - julien.benoit@wits.ac.za 


\section{Abstract}

15 Dinocephalian therapsids are renowned for their massive, pachyostotic and ornamented skulls

16 adapted for head-to-head fighting during intraspecific combat. Synchrotron scanning of the

17 tapinocephalid Moschops capensis reveals, for the first time, numerous anatomical adaptations of

18 the central nervous system related to this combative behaviour. Many neural structures (such as

19 the brain, inner ear and ophthalmic branch of the trigeminal nerve) were completely enclosed

20 and protected by bones, which is unusual for non-mammaliaform therapsids. The nearly

21 complete ossification of the braincase enables precise determination of the brain cavity volume

22 and encephalization quotient, which appears greater than expected for such a large and early

23 herbivore. The practice of head butting is often associated with complex social behaviours and

24 gregariousness in extant species, which are known to influence brain size evolution.

25 Additionally, the plane of the lateral (horizontal) semicircular canal of the bony labyrinth is

26 oriented nearly vertically if the skull is held horizontally, which suggests that the natural position

27 of the head was inclined about $60-65^{\circ}$ to the horizontal. This is consistent with the fighting

28 position inferred from osteology, as well as ground-level browsing. Finally, the unusually large

29 parietal tube may have been filled with thick conjunctive tissue to protect the delicate pineal eye

30 from injury sustained during head butting. 
32

33

34

35

36

37

38

\section{Introduction}

Dinocephalia were middle Permian therapsids that lived some 260-265 million years ago, during the middle Permian (Rubidge and Sidor, 2001; Kemp, 2005). They were typically large-bodied carnivorous (e.g. Anteosauridae) or herbivorous (e.g. Titanosuchidae, Tapinocephalidae) species, with interdigitating incisors and a pachyostotic (thickened) and ornamented skull (Rubidge and Sidor, 2001; Kemp, 2005). The taxon name, Dinocephalia, which means 'terrible head', signifies their thickened skull roof bones and pachyostosed cranial embellishments, such as the frontoparietal shield (FPS) of Moschops, the horns of Struthiocephalus and Estemmenosuchus, and supraorbital and angular bosses of anteosaurids (Boonstra, 1936; Brink, 1958; Olson, 1962; Rubidge and Sidor, 2001; Kemp, 2005; Kammerer, 2011). The impressive thickness of the cranial vault and the development of pachyosteosclerotic horn-like bosses in tapinocephalid dinocephalians highlight their morphological adaptation for direct and potentially intense headto-head combat (Barghusen, 1975; Benoit et al., 2016a). Recognition of the adaptations for head butting in these dinocephalians was not an easy task. Although head butting is a rather common practice among extant ungulates, comparisons with the fossil record are complicated as head butting encompasses a wide variety of behaviours, and because the horns, antlers and bosses of ungulates that are used for fighting are mostly made of keratin, which does not readily fossilize (Geist, 1966; Emlen, 2008; Benoit et al., 2016a). Moreover, unlike dinocephalians, the osseous correlates of ungulates are not made of compact bone, but rather filled with air sinuses (Geist, 1966; Emlen, 2008; Farke, 2008, 2010; Benoit et al., 2016a). Cranial fighting surfaces made of compact bone are encountered in odontocetes only, particularly in the maxillary crests of the bottlenose whale (Hyperoodon ampullatus) (Gowan and Rendell, 1999; Lambert et al., 2011; 
54 Biannucci et al., 2013). This has resulted in the lack of clear extant analogues to the cranial

55 specialisations of dinocephalians.

More than half a century passed after the name Dinocephalia was coined (Seeley, 1894) before Brink (1958) and Barghusen (1975) hypothesized that dinocephalian cranial features were adaptations for intraspecific head butting contests. Barghusen (1975) pointed out that the robust architecture of the skull (with its thickened skull roof, post-orbital bar, and temporal arch) was an adaptation to accommodate direct impacts on the cranial vault. He also argued that the anteroventral position of the occipital condyle (and the resulting anterior position of the quadrate condyle) resulted in a forward inclination of the skull (with the nose pointing downward and the FPS facing forward) that places the neck, the foramen magnum and the FPS in the same plane. This allowed the impact surface of the skull to be aligned with the neck during combat so that energy resulting from blows was transferred and dissipated from the dermatocranium directly to the vertebral column (Barghusen, 1975). Supraorbital thickening to absorb mechanical stress in super-carnivorous species as been invoked to explain pachyostosis of this region of the skull in anteosaurids (Kammerer, 2011), but at least for tapinocephalids (and for Moschops more particularly), Barghusen's morpho-functional reconstruction has convinced most scholars, and the head butting theory is now generally accepted (e.g. Geist, 1972; Carroll, 1988; King, 1988; Rubidge and Sidor, 2001; Kemp, 2005; Benton, 2005; Benoit et al., 2016a).

Given the current state of knowledge, it is hypothesized that head butting profoundly altered the cranial osteology of head butting dinocephalians, allowing the cranium to not only physically resist violent impacts that could smash regular bone, but also to protect the delicate central nervous system (CNS) (Benoit et al., 2016a). Accordingly, the CNS may have also been modified to withstand these blows and maintain functionality under the same conditions. It may 
77 thus be expected that the brain endocast and other osseous structures which reflect CNS

morphology, such as the bony labyrinth and cranial nerves, may be highly modified in head butting dinocephalians compared to the usually conservative CNS morphology in other nonmammalian therapsids (NMT) and Mesozoic mammals (Olson, 1944; Kemp, 1969, 1979, 2009; Sigogneau, 1970, 1974; Jerison, 1973; Hopson, 1979; Quiroga, 1980, 1984; Luo, 2001; KielanJaworowska et al., 2004; Rowe et al., 2011; Castanhinha et al., 2013; Rodrigues et al., 2013a, b; Laaß, 2015). In addition, it would be of interest for palaeobiological reconstructions to determine how the modified posture of the head and the resulting cranial remodelling (e.g. change in position and orientation of the supraoccipital plate), have affected the positioning of the brain cavity and bony labyrinth relative to the skull. The morphology of the lateral semicircular canal of the bony labyrinth would be especially relevant for this purpose, as it usually remains horizontal with respect to the ground surface when the head is in its 'natural' alert position (Girard, 1929; Giffin, 1989; Witmer et al., 2003, 2008; Sereno et al., 2007; Araujo et al., 2016). Finally, head butting often involves ritualized display, intimidation ceremonies and other complex, social behaviours (Geist, 1966; Emlen, 2008), suggesting that head butting dinocephalians expressed significant behavioural complexity (Geist, 1972), that may be reflected by the relative size of their brain (Jerison, 1973; Pérez-Barbería and Gordon, 2005).

In order to explore these hypotheses, here we analysed the very first synchrotron scans ever performed on a dinocephalian, a sub-adult Moschops capensis (Fig. 1). Moschops capensis is a tapinocephalid dinocephalian from the Tapinocephalus Assemblage Zone (late Permian, Wordian, $265 \mathrm{Ma}$ ) of the Beaufort Group of the South African Karoo. This study aims to elucidate potential modifications of the CNS that may be adaptations allowing for combative behaviour in this species. 
Material and methods

102

103

104

105

106

107

108

109

110

111

112

113

114

115

116

117

118

119

120

121

122

Specimen AM 4950 (Fig. 1) is a nearly complete skull preserved with mandibles. The right side is heavily weathered but the left side is perfectly preserved (except for the supraorbital boss). It was found on the farm The Grant 39 (Tapinocephalus Assemblage Zone, late Permian, Wordian, $\sim 265 \mathrm{Ma}$ ), north of Grahamstown, and is housed in the Albany Museum (Grahamstown, South Africa). It was preliminarily assigned to an anteosaurid prior to preparation (Modesto et al., 2001), but is now considered to be a sub-adult specimen of Moschops capensis (Benoit et al., 2016a) based on the lack of a developed canine tooth, presence of talons and heels on all the teeth, broad intertemporal surface, massive postorbital bar, absence of naso-frontal boss, incomplete development of the supraorbital bosses and the unfused state of most cranial sutures, including the bones making up the fronto-parietal shield (FPS). The basal skull length of AM 4950 is $34.02 \mathrm{~cm}$, which indicates that this individual had already reached adult size (basal skull length in adult Moschops capensis usually approximates 32-38 cm [Gregory, 1926; Barghusen, 1975; Quiroga, 1980]). Hence, despite the somehow unfused states of many of its cranial sutures, the anatomy of this sub-adult specimen is likely to reflect that of a fully grown adult. This skull was scanned in two parts at the European Synchrotron Radiation Facility (Grenoble France), first the snout in 2007, and then the braincase in 2015. The temporary export of the material for scanning was allowed by the South African Heritage Resources Agency (cases 8090 and 8560).

The anterior portion of the skull of AM4950 was scanned on the ID17 beamline of the ESRF (proposal EC192, 2007) using propagation phase contrast synchrotron radiation microtomography (PPC-SR $\mu \mathrm{CT}$ ). The setup consisted of a monochromatic beam at $96.5 \mathrm{keV}$ (single Laue crystal) from a W150 wiggler (gap 34mm), $5 \mathrm{~m}$ of propagation (sample-detector 
123 distance), a tapered fiber optic scintillator, an x0.3 magnification set of lenses and a FReLoN-

$1242 \mathrm{k} 14 \mathrm{CCD}$ camera producing data of $45.5 \mu \mathrm{m}$ voxel size. The tomography was reconstructed

125 based on 5000 projection of $0.5 \mathrm{~s}$ exposure each over 360 degrees with the center or rotation

126 shifted near the edge of recorded radiographs to almost double the horizontal reconstructed field

127 of view. Additionally the fossil was set in a tube filled in with $5 \mathrm{~mm}$ Al balls to homogenize

128 attenuation and increase exposure while preventing saturation of the detector (i.e. attenuation

129 protocol). Tomographic reconstructions were done with the program PyHST which generated a

130 stack of 16 bits TIF files. Ring corrections was performed on this stack of TIF files. Finally data

131 were binned to produced an isotropic voxel size of $91 \mu \mathrm{m}$ to reduce the overall load on computer

132 for segmentation.

133 The braincase of this skull was scanned at the ID17 beamline of the European Synchrotron

134 Radiation Facility (ESRF, Grenoble, France; proposal ES339). The setup consisted of a

135 FReLoN-2eV camera, a 0.5x magnification set of lenses, a $2 \mathrm{~mm}$ LuAG scintillator, a

136 monochromatic X-ray beam of $150 \mathrm{keV}$ (bent double-Laue crystals) and a sample-detector

137 distance of $10.9 \mathrm{~m}$ to perform Propagation Phase Contrast Synchrotron micro Computed

138 Tomography (PPC-SR $\mu \mathrm{CT})$. The tomography was computed based on 2510 projections $(58 \mathrm{x}$

1391024 pixels, binning factor of 2 ) of $0.5 \mathrm{~s}$ each over 360 degrees resulting in data with a 117.23

$140 \mu \mathrm{m}$ isotropic voxel size. An attenuation protocol (Carlson et al., 2011) allowed an increase in the

141 exposure time, to compensate for X-ray attenuation by the sample, without saturating the

142 detector. Additionally, the centre of rotation was shifted by $\sim 35 \mathrm{~mm}$ to increase the horizontal

143 field of view in the reconstructed data (i.e., half acquisition protocol). Given the limited vertical

144 field of view, 50 scans were necessary (30\% of vertical overlap between two consecutive scans)

145 to cover the full height of the sample. Tomographic reconstruction was performed using the 
146 single distance phase retrieval approach of the software PyHST2 (Paganin et al., 2002, Mirone et

147 al., 2014). The resulting 32 bits data were converted to a stack of 16 bit tiffs using the min and

148 max crop values from the 3D histogram generated by PyHST2.

149 The complete scans of both the snout and cranium can be accessed on the ESRF webstite:

150 http://paleo.esrf.fr/picture.php?/2296/category/1753

151 Three-dimensional renderings of the internal structure of the maxillary canal, bony labyrinth and

152 braincase of Moschops were achieved using manual segmentation under Avizo 8 (FEI VSG,

153 Hillsboro OR, USA). All measurements, CT images and 3D rendering were obtained using

154 Avizo 8 (FEI VSG, Hillsboro OR, USA). Following Benoit et al. (2016b), the branches of the

155 trigeminal canals were named after the corresponding branches of the trigeminal nerve in

156 mammals (see Benoit et al., 2016b for a discussion).

\section{Endocast volume, body mass and encephalization quotient:}

158 Measurements of endocranial volume were taken using Avizo 8 (FEI VSG, Hillsboro OR, USA).

159 Since the olfactory bulbs are not ossified in AM4950 or in any other NMT, endocast volume was

160 measured excluding the olfactory bulbs and tracts, as was commonly done in earlier studies (e.g.

161 Jerison, 1973; Quiroga, 1980, 1984; Kielan-Jaworowska et al., 2004; Rowe et al., 2011;

162 Rodrigues et al., 2013). The volume of the bony labyrinth was also excluded. Previously

163 published accounts regarding endocranial volume in therapsids included the pineal tube as part

164 of the endocast (Boonstra, 1968; Jerison, 1973; Quiroga, 1980, 1984; Kielan-Jaworowska et al.,

165 2004; Rowe et al., 2011; Castanhinha et al., 2013; Laaß, 2015). Thus, even though the pineal

166 tube is enormous and contributes a significant portion of the volume of the endocast in

167 Moschops, the endocast volume in this study includes the pineal tube in order to allow 
168 comparisons with previously published datasets on therapsid endocast volume (a measure of the 169 endocast volume excluding the pineal tube is nevertheless provided for comparison, Table 1). that of other therapsids (Table 1). As endocranial volume cannot be compared directly between species of differing body mass, we used the encephalization quotient (EQ) for comparative

173 purposes (Jerison, 1973; Manger, 2006; Hurlburt et al., 2013). The EQ is the ratio between the 174 endocast volume of a given animal and the expected volume of the endocast for an animal of 175 similar body mass (Jerison, 1973; Manger, 2006; Hurlburt et al., 2013). We used three different 176 types of EQ calculations in our dataset. First, Jerison's (Jerison 1973) EQ,which is calculated as 177 follows:

178 Jerison's $\mathrm{EQ}=\left(\right.$ endocast volume in $\left.\mathrm{cm}^{3}\right) /\left(0.12 *(\text { body mass in } \mathrm{g})^{2 / 3}\right)$

179 This is the most commonly used EQ in the literature, but since Jerison's EQ is often criticised as 180 it is based on a visually, rather than a mathematically, fitted regression line, we also used the 181 regression equation for calculating EQ from Manger (2006). This is considered more accurate as 182 it is defined mathematically. Though they give similar results, Manger's EQ is preferred over 183 Eisenberg's EQ (Eisenberg, 1981) because it incorporates more species into the calculation of 184 the regression equation, and excludes outliers such as primates and cetaceans. It is expressed as 185 follows:

186 Manger's EQ= (endocast volume in $\left.\mathrm{cm}^{3}\right) /\left(0.0535^{*}(\text { body mass in } \mathrm{g})^{0.7294}\right)$

187 Both these EQ calculations were determined to compare relative brain size across mammals.

188 Since early therapsids are known to have endocranial volumes closer to that of extant reptiles 189 than mammals (Jerison, 1973; Quiroga, 1980, 1984; Kielan-Jaworowska et al., 2004; Rowe et 
190 al., 2011; Rodrigues et al., 2013), we used a third expression of EQ calculated by Hurlburt et al.

191 (2013), which is adapted to the comparison of smaller endocranial volumes. This EQ is

192 calculated as follows:

193 Hurlburt et al.'s EQ= (endocast volume in $\left.\mathrm{cm}^{3}\right) /\left(0,0155^{*}(\text { body mass in } \mathrm{g})^{0,553}\right)$

194 This EQ usually gives higher values due to the dataset on which the regression is based. In all 195 cases, the larger the brain relative to the predicted brain size, the larger the EQ.

196 When available, body mass was taken from the literature (see Table 1). For Moschops,

197 Struthiocephalus and Lystrosaurus, body mass was calculated based on skull length because

198 post-cranial material for corresponding individuals was not available. We used three different

199 equations from the literature to estimate body mass. The first equation is that of Quiroga (1980,

200 1984) which was used to compare the relative endocast volume in cynodonts:

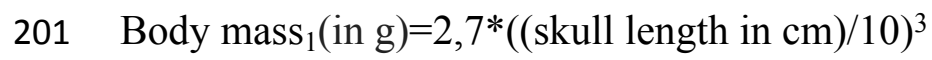

202 The second was used by $\mathrm{Hu}$ et al. (2005) to address the evolution of body size in early mammals:

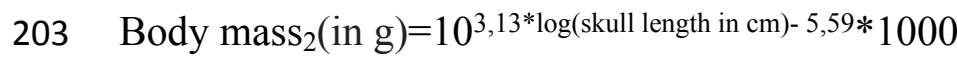

204 The third equation was used by Castanhinha et al. (2013) and consists of an indirect estimation 205 of the femur length based on skull length in order to estimate body mass. This equation is based 206 on the strong correlation that exists between skull length and femur length in NMS (Sookias et 207 al., 2012). This correlation allows the estimation of femoral length using skull length based on 208 the regression line of skull length over femoral length provided by (Sookias et al., 2012). Body 209 mass is then calculated using the estimated femoral length employing the equation of Campione 210 and Evans (2012). The complete expression of the equation summarizing the full process of 211 conversion from skull length to femoral length to body mass is written as follows: 
212 Body $\operatorname{mass}_{3}($ in $g)=10^{(2,9307 *(\log (0,6908 *(\text { skull length in } \mathrm{cm})+4,3337))-2,1677)}$

213 Though based on an indirect estimation of femoral length, this equation gives body masses that

214 are consistent with the other two methods (Table 1). We used the average of these three results to

215 obtain a body mass that was then used to calculate the EQs.

216 The results of this new method of body mass calculation were compared to those of previous

217 studies for specimens for which a skull length and a body mass were available in the literature

218 (Table 1, taxon marked with a *). For those specimens, our method gave estimates that are

219 consistent, yet a little higher, than in previous studies (Table 1). The only exceptions were the

220 dinocephalians. The body masses calculated for Moschops and Struthiocephalus are $129 \mathrm{~kg}$ and

$221288 \mathrm{~kg}$ respectively, which appear low compared to the previous estimations given by Bakker

222 (1975). Indeed, Bakker (1975) argued that Moschopid may have weighed around $700 \mathrm{~kg}$ and

223 Struthiocephalid around $1000 \mathrm{~kg}$, but the methods and specimens he used to reach these

224 conclusions are unknown. These make this sole published body mass estimate for these taxa

225 unreliable. Nevertheless, it points out that our own results may be underestimated. Based on

226 Jerison's (1973) equation to estimate body mass in animals with "heavy habitus", which is

227 expressed:

228 Body mass $($ in $\mathrm{g})=0.043 *(\text { BodyLength in } \mathrm{cm})^{3.03}$

229 and using a body length of $186.7 \mathrm{~cm}$ as measured from the tip of premaxilla to the posterior tip

230 of ilium by Gregory (1926) on the mounted skeleton of the adult Moschops capensis AMNH

2315552 , the estimated body mass of an adult sized Moschops capensis should be approximately

$232327.4 \mathrm{~kg}$. This other estimate is consistent with the possibility that the body masses calculated

233 above for dinocephalians are underestimated. Given that the basal skull length of our specimen

234 of Moschops is equivalent to that of an adult specimen, this discrepancy between our estimation 
235 and that based on Gregory's specimen might not be explained by the sub-adult age of our

236 specimen. It is more likely the result of a bias induced by the fact that all the equations we used

237 to derive body masses from skull lengths were designed for small sized animals and thus give

238 poor results for large herbivores such as dinocephalians.

239 As such, in order to take these discrepancies into account in our discussion, the EQs of Moschops

240 and Struthiocephalus were also calculated using the body masses given by Bakker (1975) and

241 that given by Jerison's equation (this last calculation was performed for Moschops only since

242 there is no mounted complete skeleton of Struthiocephalus).

\section{Description and comparisons}

245 For clarity, the orientation of all endocranial structures described here are based on the assumption that the skull was held with an inclination of $60-65^{\circ}$ from the horizontal to reflect the

247 hypothesized natural alert posture of the animal (see discussion). The term endocast is used to

248 describe the internal mould of the brain cavity only.

\section{Braincase and endocast}

250

In NMT the endocast is incomplete because ossification is limited to the dorsal aspect of the

251 braincase, and the ventral part is ossified only posterior to the pituitary fossa (Olson, 1944; Kemp, 1969, 1979, 2009; Hopson, 1979; Gow, 1986; Kielan-Jaworowska et al., 2004; Rowe et al., 2011; Castanhinha et al., 2013; Rodrigues et al., 2013a; Laaß, 2015). In some taxa, the sphenethmoid complex (mostly the orbitosphenoid, in addition to the mesethmoid rostrally, the inter-orbital septum ventrally, and the epipterygoid caudally) forms a gutter that partially ossifies ventrally around the forebrain but still leaves the metopic fissure, a wide gap between the 
257 sphenethmoid complex and basicranium, unossified (Boonstra, 1968; Hopson, 1979;

258 Ivakhnenko, 2008) (note that the metopic fissure can be reduced in some rubidgeine

259 gorgonopsians and some biarmosuchians too [Sigogneau, 1970]). In contrast, the skull of

260 Moschops and other tapinocephalids is more robustly built than in most NMT (Boonstra, 1968;

261 Benoit et al., 2016a). At the level of the braincase, the cranial vault comprises 50 to $60 \mathrm{~mm}$ thick

262 bone divided into a 15 to $20 \mathrm{~mm}$ osteosclerotic surface forming the FPS and about $40 \mathrm{~mm}$ of

263 internal cancellous bone (Fig. 2) (Benoit et al., 2016a). Unlike the condition in other NMT, in

264 dinocephalians the sphenethmoid complex and basicranium share a suture, are pachyostotic and

265 cancellous, and the braincase is also completely ossified ventrally (Fig. 2) (Boonstra, 1968;

266 Benoit et al., 2016a). As a consequence, the endocast is complete in Moschops, contrary to that

267 of other NMT.

268 The endocast volume in this sub-adult specimen of Moschops capensis is $61 \mathrm{~cm}^{3}\left(40 \mathrm{~cm}^{3}\right.$

269 excluding the pineal tube which is $21 \mathrm{~cm}^{3}$ ), which is close to the $65 \mathrm{~cm}^{3}$ measured in an adult

270 specimen of the more derived tapinocephalid Struthiocephalus whaitsi (Table 1). Unlike other

271 NMT (Kemp, 1969, 1979, 2009; Hopson, 1979; Kielan-Jaworowska et al., 2004; Rowe et al.,

272 2011; Castanhinha et al., 2013; Rodrigues et al., 2013a; Laaß, 2015), the main axis of the

273 endocast is not aligned with that of the skull but appears nearly horizontal when the skull is

274 inclined at about $60^{\circ}$ from horizontal (Figs. 1C). This inclination of the braincase compared to

275 the rostrum is present to various degrees in all dinocephalians in which the braincase has been

276 studied (Barghusen, 1975; Boonstra, 1968; Ivakhnenko, 2008). The endocast is serially arranged

277 in Moschops (Fig. 3A-C). The cerebral part of the endocast is short and the hemispheres are not

278 distinct on its surface (Fig. 3A, B), which means that the cerebral hemispheres were probably

279 small and that the brain was likely separated from the braincase by a thick layer of adnexa, most 
280 likely composed of meningeal tissue as well as arteries and venous sinuses (Bauchot and

281 Stephan, 1967).

282 Concerning the olfactory bulbs, only the bony canals that house the olfactory tracts are ossified

283 and are reconstructed here (Fig. 3A-C). Because of the ventral ossification of the braincase, the

284 endocast of Moschops preserves canals for many nerves and other soft tissue structures that are

285 not usually seen on the endocasts of other NMT. For instance, a discrete canal for the optic nerve

286 is present, which is unique to dinocephalians (Fig. 3B) (Boonstra, 1968). The metopic fissure is

287 reduced to the passages of the middle cerebral vein and the root of the trigeminal nerve, as in

288 other Dinocephalia (Boonstra, 1968). However, in AM4950 these passages are completely

289 separate, resulting in two distinct canals, a dorsal one for the middle cerebral vein and a ventral

290 one for the root of the trigeminal nerve (Fig. 3B).

291 A number of large canals, possibly for emissary veins, run from the surface of the FPS to the

292 endocast (Fig. 1B). The pineal tube is prominent in Moschops and completely covers the

293 midbrain in dorsal view (Fig. 3C). This tube is oriented slightly rostrally compared to the

294 endocast and the parietal foramen opens right above the midbrain, as in other NMT (Olson,

295 1944; Kemp, 1969, 1979, 2005, 2009; Boonstra, 1968; Quay, 1979; Hopson, 1979; Kielan-

296 Jaworowska et al., 2004; Castanhinha et al., 2013; Laaß, 2015), but compared to the skull it

297 opens on the caudal margin of the cranial roof (Figs. 1B, C). Moschops and other dinocephalians

298 are very distinctive because of their hypertrophied and deep hypophyseal fossa (Fig. 3A, B)

299 (Boonstra, 1968). Unlike other NMT, in dinocephalians the hypophyseal fossa is completely

300 ossified rostrally by the presphenoid, and its boundaries are well defined (Fig. 3A, B) (Boonstra,

301 1968). The hypophyseal fossa occupies a volume of $1.51 \mathrm{~cm}^{3}$. In this sub-adult Moschops the

302 hypophyseal fossa is not bulbous, as in the adult Moschops and other tapinocephalids described 
303 by Boonstra (Boonstra, 1968), but it is long and slender, similar to the condition in Jonkeria and

304 Anteosaurus (Fig. 3A, B) (Boonstra, 1968). The base of the hypophyseal fossa is pierced by the

305 foramen that transmitted the internal carotid arteries (Fig. 3A, B). The stylomastoid canal for the

306 facial nerve is long and located anterior to the bony labyrinth (Fig. 3B). A discrete jugular

307 foramen, for the cochlear canaliculus and the glossopharyngeal and vagus nerves, is found

308 immediately posterior to the bony labyrinth (Fig. 3B). There is a clear osseous separation

309 between the vestibule of the bony labyrinth and the jugular foramen. This is a rare condition

310 amongst NMT, but it has been observed in gorgonopsians and an indeterminated dinocephalian

311 previously (Haugthon, 1918; Sigogneau, 1974; Luo, 2001). The canals for the accessory and

312 hypoglossal nerves are separate (Fig. 3B). There is a distinct pontine flexure of the endocast

313 between the hindbrain and the foramen magnum (Fig. 3A, B). The floccular fossa is shallow in

314 Moschops (Fig. 3A), as in other dinocephalians (Boonstra, 1968). It is encircled by the anterior

315 semicircular canal of the bony labyrinth.

\section{Bony labyrinth}

317 The right side of the braincase is best preserved in AM4950, but the bony labyrinth is complete

318 only on the left side (Fig. 1C, 3D). The vestibule in Moschops is long and conical (Fig. 3D) and a

319 small and circular fenestra vestibuli opens on its distal extremity (Fig. 3D). There is no evidence

320 for a cochlear recess or canal. The medial ossification of the common crus, anterior ampulla and

321 vestibule is not complete in AM4950, which results in a large unossified area between the

322 endocast and bony labyrinth (Fig. 2). In contrast, adult dinocephalian skulls studied by Boonstra

323 (Boonstra, 1968) have only a small and discrete internal auditory meatus for the vestibulo-

324 cochlear nerve, which shows that in adult specimens the bony labyrinth and the braincase are

325 separate. The ampullae are inconspicuous in Moschops (Fig. 3D), the secondary common crus 
326 between the anterior and posterior semicircular canal is long (Fig. 3D), and the anterior

327 semicircular canal appears to be the largest as it projects further dorso-caudally than the posterior

328 canal (Fig. 3D). The lateral semicircular canal forms an angle of about $105-115^{\circ}$ with the main

329 axis of the skull (Fig. 1C) which suggests that the actual natural position of the head was more

330 vertical rather than horizontal (see discussion).

\section{Trigeminal canals}

332 As in other NMT, the trigeminal canals are divided into ophthalmic, maxillary and mandibular

333 branches housing the corresponding rami of the trigeminal nerve and accompanying vessels (Fig.

334 4) (see Benoit et al., 2016b for a discussion about the homology of these structures). Although

335 the path of the trigeminal nerve from its root (Fig. 3B) to the trigeminal canals (Fig. 4) is not

336 preserved, the three ramifications are readily identifiable. The maxillary canal is more ramified

337 than that of any other NMT in which it has been documented (Benoit et al., 2016b); however, it

338 comprises essentially the same branches as in other taxa. As in most other NMT, three alveolar

339 rami innervate the lip above the maxillary teeth (Fig. 4). These rami are oriented rostrally instead

340 of ventrally, likely in response to the elaborated development of the rostral dentition in

341 tapinocephalids. There is an important postero-dorsal extension of the external nasal ramus,

342 which reaches the bone surface caudal to the external naris (Fig. 4). The internal nasal and

343 superior labial rami reach the rostral-most margins of the maxilla (Fig. 4). The ophthalmic

344 branch is exceptionally well preserved in Moschops, with clearly identifiable frontal and nasal

345 rami, which is a rare condition amongst NMT (Benoit et al., 2016b). Indeed, with the noticeable

346 exception of Thrinaxodon liorhinus, the route of the ophthalmic nerve is usually not ossified in

347 NMT and only short and isolated bony channels that go through the nasal and frontal bones mark

348 its presence (Benoit et al., 2016b). As in Thrinaxodon, both the frontal and nasal rami are 
ossified, but they do not innervate the same area. In Moschops, the nasal ramus ramifies inside, and opens on the surface of the premaxilla instead of the nasal bone as in Thrinaxodon (Fig. 4). In a similar manner, the frontal ramus ramifies more rostrally than in Thrinaxodon and opens on the surface of the nasal bone in Moschops, instead of the frontal bone (Fig. 4). Nevertheless, it is possible that some of the canals identified for emissary veins in Figure 1 could also have carried some branches of the frontal ramus, though it is unlikely given they do not branch to the canal identified here as the frontal ramus. As for the maxillary canal, the mandibular canal has numerous branches that open into many mental foramina on the surface of the dentary (Fig. 4).

\section{Discussion}

\section{Bony labyrinth and head posture}

The bony labyrinth in Moschops is very unusual amongst NMT because compared to other NMT in which all semicircular canals look similar, the bony labyrinth of Moschops displays a distinctly larger anterior semicircular canal, a character also commonly encountered in archosaurs (Hopson, 1979; Witmer et al., 2003; 2008; Walsh et al., 2013) and mammals as well as in the sister taxon of Mammaliaformes, Brasilitherium (Olson, 1944; Kemp, 1969, 1979, 2009; Hopson, 1979; Gow, 1986; Luo, 2001; Kielan-Jaworowska et al., 2004; Castanhinha et al., 2013; Rodrigues et al., 2013b; Laaß, 2015; Ekdale, 2015). Thirdly, Moschops differs from other NMT because the plane of the lateral semicircular canal is not oriented in roughly the same direction as the as the main axis of the skull (Fig. 1C). As a result, the plane of the lateral semicircular canal is oblique with respect to the horizontal when the skull is held as in most reconstructions (Fig. 5A), whereas a more natural position for the head would be with the plane of the lateral canal closer to the horizontal, parallel to the substrate surface plane $\pm 10^{\circ}$ (Girard, 
372 1929; Vidal et al., 1986; Sereno et al., 2007; Witmer et al., 2008; but see Marugán-Lobón et al.

373 (2013) and Araujo et al. (2016) for a discussion in the context of NMT). The reconstructed

374 natural alert position of the head is shown in Figure 5B. According to this new reconstruction,

375 the skull would have been held with the rostrum pointing downward in Moschops because in this

376 position, the occiput comfortably articulates with the cervical vertebrae (Barghusen, 1975;

377 Kemp, 2005). This head posture also positions the FPS facing forward, which is consistent with

378 the reconstructed head butting combat habits of tapinocephalids (Barghusen, 1975) and would

379 have facilitated ground-level browsing in these herbivorous animals (Sereno et al., 2007). If the

380 head was ordinarily held with the snout lowered down as it is here suggested, this would strongly

381 contradict a semi-aquatic habitat as has been often advocated for tapinocephalids (see King, 1988

382 for a review).

383 As early as 1958, Brink (1958) noted that in Struthiocephalus, the braincase is tilted posteriorly

384 so that the FPS, the foramen magnum, and the vertebral column were aligned during fighting

385 (Barghusen, 1975). This allowed for the transfer of energy to the vertebral column as a result of

386 head butting (Fig. 6) (Barghusen, 1975; Benoit et al., 2016a). This posterior re-orientation of the

387 braincase is particularly pronounced among tapinocephalids (Boonstra, 1968; Ivakhnenko,

388 2008). The tilted condition of the braincase may thus be the by-product of the necessity to align

389 the FPS, foramen magnum and vertebral column during fighting, and also to displace the parietal

390 foramen away from the FPS (Barghusen, 1975; Benoit et al., 2016a). One may thus argue that

391 the orientation of the bony labyrinth does not reflect the natural head posture, but rather results

392 from this flexure of the basicranium and occiput. However, the re-orientation of the

393 dinocephalian braincase leaves the pontine flexure of the endocast unaffected, meaning that the

394 entire braincase underwent a re-orientation, not only the basicranium (Fig. 1C) (Boonstra, 1968). 
395 By comparison, in pachycephalosaurid dinosaurs, the only other reasonably known group

396 displaying a re-organisation of the skull comparable to tapinocephalids, this alignment is

397 achieved by the loss of the pontine flexure (Fig. 7A) which enables the foramen magnum to be

398 positioned right at the base of the skull (Giffin, 1989; Bourke et al., 2014). However, this leaves

399 the braincase and bony labyrinth in the same orientation as the skull (Fig. 7B) (Giffin, 1989;

400 Bourke et al., 2014). This indicates that a complete re-orientation of the braincase is not a

401 necessity to align the FPS with the foramen magnum and the neck, thus supporting the

402 hypothesis that the rotation of the bony labyrinth and braincase is not simply an epiphenomenon.

403 It must be noted here that the backward rotation of the braincase is not unique to dinocephalians

404 as it is also evolved in a convergent manner in some Kannemeyeriiformes such as Placerias,

405 Lystrosaurus and Stahleckeria (Fig.8; Camp and Welles, 1956; Lehman, 1961). Interestingly,

406 Lystrosaurus display a strong pontine flexure, like Moschops, whereas Placerias and

407 Stahleckeria do not (Fig.8; Camp and Welles, 1956; Lehman, 1961). Unfortunately, the rotation

408 of the braincase (cyptocephaly) is not a very well studied or understood phenomenon in extant

409 species (Solounias, 2007), which strongly limits this interpretation. Different degrees of

410 cyptocephaly associated with various degrees of flexure of the pons are documented in many

411 species known to practice head butting, such as artiodactyls (mostly bovids), perissodactyls and

412 proboscideans (Olson, 1929, 1942; Geist, 1966; Solounias, 2007; Badlangana et al., 2011).

413 Adaptation for foraging (grazer or browser) is often invoked to account for this pontine flexure,

414 but it remains untested and as such, adaptation to head butting and the effect of phylogeny

415 cannot be ruled out (Solounias, 2007). A better understanding of this phenomenon and its

416 ecological implications would bring crucial clues to understanding of the behaviour and

417 palaeoecology of ancient therapsid herbivores. 


\section{Protection of the CNS and modifications related to head butting}

420 Unlike NMT, the braincase completely encloses and protects the CNS in all mammals (Hopson,

421 1979; Kielan-Jaworowska et al., 2004; Rowe et al., 2011). Thus, the braincase of extant head

422 butting species resembles that of non-head butting species, though it is often covered by

423 keratinous horn sheaths and filled with enlarged paranasal sinuses that act as shock absorbers

424 (Farke, 2008, 2010; Badlangana et al., 2011) and the sutures are more ramified and interdigitated

425 (Jaslow, 1995). Dinocephalians are unique amongst NMT in having an endocast completely

426 enclosed by the bones making up the braincase (Figs 2, 3) (Boonstra, 1968). Dorsally, the cranial

427 roof is thickened and covered by a densely ossified FPS, and ventrally the bony complexes of the

428 skull base (sphenethmoid complex and basicranium) are expanded dorsally and medially toward

429 one another to enclose the braincase (Fig. 2) (Boonstra, 1968; Barghusen, 1975; Benoit et al.,

430 2016a). Unlike most other NMT, the endocast in Moschops, including the hypophyseal fossa, is

431 fully enclosed by bone. The bony labyrinth is isolated from the braincase in adults, and the roots

432 of many cranial nerves are preserved as discrete canals (Fig. 3B) (Boonstra, 1968). Only the

433 ventral aspects of the olfactory bulbs are not ossified. Previous studies on head butting in

434 Moschops have focused on morphological and histological adaptations such as the thickened

435 bones of the FPS and post-orbital bar, the roughened surface of the FPS to support a cornified

436 plate, the ventral position of the foramen magnum and inclined occiput to align the FPS with

437 neck vertebrae, and the presence of cancellous bones under the dense FPS to absorb energy and

438 lighten the skull (Barghusen, 1975; Benoit et al., 2016a). These adaptations prevented bone

439 breakage under physical forces exerted during head butting. The CNS may have also been

440 protected by the thickened orbitosphenoid, prootic and epipterygoid which appear columnar on 
441 CT cross section (Fig. 6A). Their anatomy suggests that shock waves were transfered through

442 these bones away from the brain, to the foramen magnum and the neck where they were

443 dissipated (as hypothesized on Fig. 6B). This hypothesis is solely based on comparative anatomy

444 but could be addressed in the future using a functional study based on Finite Element Analysis

445 (FEA) and a broader taxonomic sampling of dinocephalians.

446 Moreover, since the brain was likely not in direct contact with the braincase in Moschops, as

447 indicated by the absence of impressions of the nervous tissue on the endocast (Fig. 3A-C), they

448 might have been separated by a thick layer of soft tissue (adnexa), presumably meninges, blood

449 vessels (such as the emissary veins), and other conjunctive and protective tissues that surrounded

450 the brain and helped to absorb vibrations.

451 Adnexa may have occupied much of the pineal tube as well. This tube is comparatively large in 452 Moschops, occupying 35\% of the volume of the complete endocast (Fig. 3A, B; Table 1). The 453 parietal tube and foramen housed the membranous pineal nerve and pineal eye (or third eye) 454 (Edinger, 1955; Quay, 1979; Roth et al., 1986; Benoit et al., 2016c). In extant reptiles, these 455 delicate nervous structures monitor biological cycles and rhythms (Quay, 1979; Roth et al., 456 1986). Hopson (1979) argued that the enlarged parietal foramen and the correspondingly large 457 diameter of the pineal tube in dinocephalians might have been for a large pineal eye and nerve. 458 However, in the case of head butting species, the enlarged parietal tube and foramen is more 459 likely to have housed a thick sheath of soft tissue to isolate and protect the pineal eye and nerve 460 from injury during combat. Another possibility is that the large pineal tube was filled with 461 cerebrospinal fluid and operated as a pressure relief window to shunt shocks out of the braincase 462 like the round fenestra act as a pressure relief window for the inner ear (Luo et al., 2016). 
463 The complete ossification of a bony tube for the dorsal-most branch of the trigeminal nerve (the

464 ophthalmic branch) may also reflect a protective adaptation related to this part of the CNS. In

465 addition, the ophthalmic branch appears to have shifted rostrally in Moschops (Fig. 4), maybe for

466 distancing the ophthalmic nerve (particularly its frontal ramus) and accompanying vessels from

467 the FPS where they could have been injured and triggered pain and bleeding during combat.

468 Therefore, the nasal branch of the ophthalmic canal appears to have shifted to the premaxilla, 469 and the frontal branch appears to have shifted to the nasal bone in order to avoid the surface of 470 the FPS (Fig. 4).

\section{Endocast volume and behaviour}

472 As dinocephalians display a unique degree of ossification of the braincase, endocast volume can

473 be measured more accurately in this taxon than in other taxa. Boonstra (1958) was the first to

474 measure the volume of the endocranial brain cavity in a dinocephalian, a specimen of

475 Struthiocephalus whaitsi. Excluding the olfactory bulbs, the endocast of Struthiocephalus whaitsi

476 is rather small at only $65 \mathrm{~cm}^{3}$ (excluding the olfactory bulbs), which given its calculated body

477 size (about $288 \mathrm{~kg}$, Table 1), makes its relative endocranial capacity among the smallest

478 according to Jerison's and Manger's EQs (Table 1); however, according to Hurlburt et al.'s EQ,

479 the Struthiocephalus endocast is among the largest for NMT (Table 1). Using Bakker's (1975)

480 body mass of one ton, the EQs of Struthiocephalus are definitely the smallest of all NMT (Table

481 1), except for Hurlburt et al.’s EQ (Table 1).

482 With an endocast of about $62 \mathrm{~cm}^{3}$ for a body mass estimated to be about $129 \mathrm{~kg}$, the relative

483 endocranial capacity of Moschops is comparatively larger than that of Struthiocephalus (Table

484 1). Depending on the EQ, the relative endocranial size of Moschops appears comparable to, or

485 larger than, that of most NMT and early mammaliaforms, such as Morganucodon and 
486

487 488 489

490

491

492

493

494

495

496

497

498

499

500

501

502

503

504

505

506

507

508

Hadrocodium (according to Jerison's EQ and Hurlburt et al.'s EQ), or it is in the average for NMT (according to Manger's EQ) (Table 1). Using the higher body mass calculated using Jerison's equation $(327 \mathrm{~kg})$, the Jerison's and Manger's EQs of Moschops still maintain a value of 0.11 (3.52 for Hurlburt et al.'s EQ), which is close to those of some cynodonts and dicynodonts (e.g. Exaeretodon, Lystrosaurus; Table 1) and is even still comparable to the lowest range of variation of EQs in mammals (Jerison, 1975; O'Shea and Reep, 1990; Manger, 2006; Benoit et al., 2013). This result is quite unexpected for such a large Paleozoic herbivore, given the general trend toward increasing encephalization observed in synapsids (Hopson, 1979; Gow, 1986; Kielan-Jaworowska et al., 2004; Rowe et al., 2011; Castanhinha et al., 2013; Rodrigues et al., 2013a; Laaß, 2015) and that mammalian herbivores usually have relatively smaller brains and because of negative allometry of brain mass scaling with body mass (Jerison, 1973; Eisenberg, 1981; Manger, 2006). The practice of head butting is often associated with ritual, social and display behaviours, and a hierarchical society in extant gregarious species (Geist, 1966). Such complex behaviour, though currently without evidence for Dinocephalia, are known to drive selection for greater brain size in extant ungulates (Geist, 1972; Pérez-Barbería and Gordon, 2005).

Nevertheless, the endocast volume and EQs of dinocephalians must be interpreted with caution because of the large discrepancies in body mass estimations. Here, using the (probably overestimated) mass of $700 \mathrm{~kg}$ advocated by Bakker (1975), the EQs in Moschops are unremarkably low (Table 1). In addition, as stated above, the brain did not fill the braincase and thus the endocast volume does not reflect brain size as accurately as it does in mammals. Moreover, the large volume of the pineal tube plays an important role increasing endocast volume as shown by the calculations of EQs where the pineal tube is removed (Table 1). Finally, 
509 the hypertrophied hypophyseal fossa also contributes to the volume of the endocast $(2.57 \%$,

$5103.80 \%$ when excluding the volume of the pineal tube; Table 1). Nopcsa (1926) and Boonstra

511 (1958) argued that the large size of the hypophyseal fossa in dinocephalians may reflect the

512 degree of cranial pachyostosis. This would make this character relevant for a discussion about

513 neurological adaptations to head butting, but a similarly hypertrophied hypophyseal fossa is

514 present in many sauropod dinosaurs and other large extinct species in which the skull is not

515 pachyostotic (Edinger, 1942). As the hypophyseal fossa houses the pituitary gland, which

516 secretes growth hormones, and since an hypertrophied fossa seems to be present in mostly

517 gigantic species (Edinger, 1942; but exceptions exist [Macrini et al., 2007]), it is more likely that

518 in dinocephalians the size of this fossa may be correlated with large body size rather than cranial

519 pachyostosis.

\section{Concluding remarks}

522 The skulls of tapinocephalid dinocephalians exhibit extensive adaptations for head butting

523 combat, to the extent that complete ossification and re-orientation of the braincase sets them

524 apart from all other NMT. Intraspecific head butting combat is considered a sexually selected

525 behaviour, but the effect of sexual selection and related behaviours are difficult to define and

526 reconstruct from the fossil record. Therefore the recognition and identification of neural

527 characters that facilitate head butting behaviour in Moschops are crucial for future

528 palaeobiological studies of NMT. These characters include the complete bony enclosure of the

529 endocast, bony labyrinth and ophthalmic branch of the trigeminal nerve, a $105-110^{\circ}$ inclination

530 of the skull compared to the plan of the lateral semicircular canal, an anterior placement of the

531 ophthalmic canal, and the enlargement of the parietal tube. Given the relatively large number of 
532 NMT taxa that manifest signs of head butting behaviour (Benoit et al., 2016a), recognition of

533 such adaptations will certainly change the way the daily life of these long-extinct animals are

534 imagined and also shed new light on the ancestry of mammalian behaviour and sociality.

535

\section{Acknowledgements}

537 We thank B. De Klerk and the Albany Museum for the specimen loan, Dr. R. Redelstorff for 538 help with SAHRA regulation and S. Jasinoski (ESI) for advice. We acknowledge the European

539 Synchrotron Radiation Facility for provision of synchrotron radiation facilities and we would

540 like to thank P. Tafforeau for assistance in using beamline ID17. We also thank the three

541 reviewers, S. Lautenschlager, C. Kammerer and S. Walsh. SAHRA PermitID: 2060.

\section{References}

544 Araujo, R. M., Fernandez, V., Polcyn, M. J., Fröbisch, J. and Martins, R. M. S. 2016. Aspects of

545 the gorgonopsian paleobiology: insights from the basicranium, occiput, osseous labyrinth and

546 neuroanatomy of the immature gorgonopsian skull of Aloposaurus gracilis (Therapsida:

547 Theriodontia: Gorgonopsia). PeerJ Preprints 4: e2313v1.

548 Badlangana, N. L., Adams, J. W. and Manger, P. R. 2011. A comparative assessment of the size 549 of the frontal air sinus in the giraffe (Giraffa camelopardalis). The Anatomical Record 294: 931550940.

551 Bakker, R. T. 1975. Dinosaur renaissance. Scientific American 232: 58-78.

552 Barghusen, H. R. 1975. A review of fighting adaptations in dinocephalians (Reptilia, 553 Therapsida). Paleobiology 1: 295-311. 
554 Bauchot, R. and Stephan, H. 1967. Encéphales et moulages endocrâniens de quelques

555 insectivores et primates actuels. Colloque International du CNRS, 163: 575-587.

556 Benoit, J., Abdala, F., Manger, P. R. and Rubidge, B. S. 2016c. The sixth sense in mammalians

557 forerunners: Variability of the parietal foramen and the evolution of the pineal eye in South

558 African Permo-Triassic eutheriodont therapsids. Acta Palaeontologica Polonica 61: 777-789.

559 Benoit, J., Crumpton, N., Merigeaud, S. and Tabuce, R. 2013. A memory already like an

560 elephant? The advanced brain morphology of the last common ancestor of Afrotheria

561 (Mammalia). Brain Behaviour and Evolution 81: 154-169.

562 Benoit, J., Fernandez, V., Tafforeau, P., Manger, P.R. and Rubidge B.S. 2016a. Cranial bosses of 563 Choerosaurus dejageri (Therapsida, Therocephalia): earliest evidence of cranial display

564 structures in eutheriodonts. PLoS ONE 11(8) : e0161457.

565 Benoit, J., Manger, P.R. and Rubidge, B.S. 2016b. Palaeoneurological clues to the evolution of 566 defining mammalian soft tissue traits. Scientific Reports 6: 25604.

567 Benton, M. J. 2005. Vertebrate Paleontology, 3rd ed. Blackwell Science Ltd, Oxford.

568 Bianucci, G., Miján I., Lambert O., Post K., and Mateus O. 2013. Bizarre fossil beaked whales

569 (Odontoceti, Ziphiidae) fished from the Atlantic Ocean floor off the Iberian Peninsula.

570 Geodiversitas 35: 105-153.

571 Boonstra, L. D. 1936. The Cranial Morphology of Some Titanosuchid Deinocephalians. Bulletin

572 of the American Museum of Natural History 72: 99-116.

573 Boonstra, L. D. 1968. The braincase, basicranial axis and median septum in the Dinocephalia.

574 Annals of the South African Museum 50: 195-273. 
575 Bourke, J. M., Porter, W. R., Ridgely, R. C., Lyson, T. R., Schachner, E. R., Bell, P. R., and

576 Witmer, L. M. 2014. Breathing life into dinosaurs: tackling challenges of soft-tissue restoration

577 and nasal airflow in extinct species. Anatomical Record 297: 2148-2186.

578 Brink, A. S. 1958. Struthiocephalus kitchingi sp. nov. Palaeontologia African 5: 39-56.

579 Camp, C. L., Welles, S. P. 1956. Triassic dicynodont reptiles. Part I. The North American genus

580 Placerias. Memoirs of the University of California 13: 255-304.

581 Campione, N. E. and Evans, D. C. 2012. A universal scaling relationship between body mass and

582 proximal limb bone dimensions in quadrupedal terrestrial tetrapods. BMC Biology 10: 60.

583 Carlson, K.J., Stout, D., Jashashvili, T., de Ruiter, D.J., Tafforeau, P., Carlson, K. and Berger,

584 L.R. 2001. The endocast of MH1, Australopithecus sediba. Science 333 (6048): 1402-1407.

585 Carroll, R. 1988. Vertebrate paleontology and evolution. W.H. Freeman, New York.

586 Castanhinha, R., Araújo, R., Júnior, L. C., Angielczyk, K. D., Martins, G. G., Martins, R. M. S.,

587 Chaouiya, C., Beckmann, F. and Wilde, F. 2013. Bringing dicynodonts back to life: paleobiology

588 and anatomy of a new emydopoid genus from the Upper Permian of Mozambique. PLoS One

589 8(12): e80974.

590 Edinger, T. 1942. The pituitary body in giant animals fossil and living: a survey and a

591 suggestion. The Quarterly Review of Biology 17: 31-45.

592 Edinger, T. 1955. The size of parietal foramen and organ in reptiles. A rectification. Bulletin of

593 the Museum of Comparative Zoology, Harvard 114: 1-34.

594 Eisenberg, J. F. 1981. The Manunalian Radiations: An Analysis of Trends in Evolution,

595 Adaptations and Behavior. University of Chicago Press, Chicago. 
596 Ekdale, E.G. 2013. Comparative Anatomy of the Bony Labyrinth (Inner Ear) of Placental

597 Mammals. PLoS ONE 8(6): e66624.

598 Emlen, D. J. 2008. The evolution of animal weapons. Annual Review of Ecology, Evolution, and 599 Systematics 39: 387-413.

600 Farke, A. A. 2008. Frontal sinuses and head-butting in goats: a finite element analysis. Journal of 601 Experimental Biology 211: 3085-3094.

602 Farke, A. A. 2010. Evolution and functional morphology of the frontal sinuses in Bovidae 603 (Mammalia: Artiodactyla), and implications for the evolution of cranial pneumaticity. Zoological 604 Journal of the Linnean Society 159: 988-1014.

605 Geist, V. 1966. The evolution of horn-like organs. Behaviour 27: 175-214.

606 Geist, V. 1972. An ecological and behavioural explanation of mammalian characteristics and 607 their implication to therapsid evolution. Zeitschrift für Säugetierkunde 37: 1-15.

608 Giffin, E. B. 1989. Pachycephalosaur Paleoneurolagy (Archosauria: Ornithischia). Journal of 609 Vertebrate Paleontology $9: 67-77$.

610 Girard, L. 1929. Lattitude normale de la tête déterminée par le labyrinthe de l'oreille. Bulletins et 611 Mémoires de la Société d'anthropologie de Paris, VII Série 10: 79-99.

612 Gow, C. E. 1986. The sidewall of the braincase in cynodont therapsids, and a note on the 613 homology of the mammalian promontorium. South African Journal of Zoology 21: 136-148.

614 Gowans, S. and Rendell, L. 1999. Head-butting in northern bottlenose whales (Hyperoodon 615 ampullatus): a possible function for big heads? Marine Mammal Science 15: 1342-1350. 
616 Gregory, W. K. 1926. The Skeleton of Moshops capensis Broom, a Dinocephalian Reptile from 617 the Permian of South-Africa. Bulletin of the American Museum of Natural History 56: 179-251.

618 Haughton, S.H. 1918. On some new carnivorous therapsids with note upon the brain-case in 619 certain species. Annals of the South African Museum 12:175-216.

620 Hopson, J.A. 1979. Paleoneurology. Pp. 39-146, in C. Glans, R. G. Northcutt and P. Ulinski, 621 eds. Biology of the Reptilia. Academic Press, New York.

$622 \mathrm{Hu}, \mathrm{Y} .$, Meng, J., Wang, Y. and Li, C. 2005. Large Mesozoic mammals fed on young dinosaurs.

623 Nature 433: 149-152

624 Hurlburt, G. R., Ridgely R. C. and Witmer L. M. 2013. Relative Size of Brain and Cerebrum in 625 Tyrannosaurid Dinosaurs: An Analysis Using Brain-Endocast Quantitative Relationships in 626 Extant Alligators. Pp. 135-155, in J. M. Parrish, R. E. Molnar, P. J. Currie, E. B. Koppelhus, eds. 627 Tyrannosaurid Paleobiology. Indiana University Press, Bloomington.

628 Ivakhnenko, M. F. 2008. Cranial Morphology and Evolution of Permian Dinomorpha 629 (Eotherapsida) of Eastern Europe. Paleontological Journal 42: 859-995.

630 Jaslow, C. R. 1995. Strain patterns in the horncores, cranial bones and sutures of goats (Capra 631 hircus) during impact loading. Journal of Zoology 235: 193-210.

632 Jerison, H. J. 1973. Evolution of the brain and intelligence. Academic Press, New York.

633 Kammerer, C. F. 2011. Systematics of the Anteosauria (Therapsida: Dinocephalia). Journal of 634 Systematic Palaeontology 9: 261-304.

635 Kemp, T. S. 1969. On the Functional Morphology of the Gorgonopsid Skull. Philosophical 636 Transactions of the Royal Society Series B: Biological Sciences 256: 1-83. 
637 Kemp, T. S. 1979. The Primitive Cynodont Procynosuchus: Functional Anatomy of the Skull 638 and Relationships. Philosophical Transactions of the Royal Society Series B: Biological Sciences 639 285: 73-122.

640 Kemp, T. S. 2005. The origin and evolution of mammals. Oxford University Press, Oxford. 641 Kemp, T. S. 2009. The Endocranial Cavity of a Nonmammalian Eucynodont, Chiniquodon 642 theotenicus, and Its Implications for the Origin of the Mammalian Brain. Journal of Vertebrate 643 Paleontology 29: 1188-1198.

644 Kielan-Jaworowska, Z., Cifelli, R. L. and Luo, Z.-X. 2004. Mammals from the Age of Dinosaurs 645 Origins, Evolution, and Structure. Columbia University Press, New York.

646 King, G. M. 1988. Anomodontia. Handbuch der Paläoherpetologie, Vol. 17C. Stuttgart, Gustav 647 Fischer Verlag. Laaß, M. 2015. Virtual Reconstruction and Description of the Cranial Endocast of Pristerodon 649 mackayi (Therapsida, Anomodontia). Journal of Morphology 276: 1089-1099.

650 Lambert O., Buffrénil V. and Muizon C. 2011. Rostral densification in beaked whales: diverse 651 processes for a similar pattern. Comptes Rendus Palevol 10: 453-468.

652 Lehman, J.-P. 1961. Dicynodontia. Pp. 287-351, in J.-P. Piveteau, ed. Traité de Paléontologie, 653 VI, Mammifères, Vol.1 : Origine Reptilienne Evolution. Masson et Cie., Paris.

654 Luo, Z.-X. 2001. Inner ear and its bony housing in tritylodonts and implications for evolution of 655 mammaliaform ear. Bulletin of the Museum of Comparative Zoology 156: 81-97.

656 Luo, Z.-X., Schultz, J. A. and Ekdale E. G. 2016. Evolution of the Middle and Inner Ears of 657 Mammaliaforms: The Approach to Mammals. Pp. 139-174, in J. A. Clack et al., eds. Evolution 
658 of the Vertebrate Ear-Evidence from the Fossil Record. Springer Handbook of Auditory

659 Research 59, Springer International Publishing, New York.

660 Manger, P. R. 2006. An examination of cetacean brain structure with a novel hypothesis

661 correlating thermogenesis to the evolution of a big brain. Biological Reviews 81: 293-338.

662 Marugán-Lobón, J., Chiappe, L. M. and Farke, A. A. 2013. The variability of inner ear

663 orientation in saurischian dinosaurs: testing the use of semicircular canals as a reference system

664 for comparative anatomy. PeerJ 1:e124.

665 Mirone, A., Brun, E., Gouillart, E., Tafforeau, P. and Kieffer, J. 2014. The PyHST2 hybrid

666 distributed code for high speed tomographic reconstruction with iterative reconstruction and a

667 priori knowledge capabilities. Nuclear Instruments and Methods in Physics Research Section B:

668 Beam Interactions with Materials and Atoms 324: 41-48.

669 Modesto, S. P., Rubidge, B. S., de Klerk, W. J. and Welman, J. 2001. A dinocephalian therapsid

670 fauna on the Ecca-Beaufort contact in Eastern Cape Province, South Africa. South African

671 Journal of Science 97: 161-163.

672 Nopcsa, F. 1926. Heredity and Evolution. Proceedings of the Zoological Society of London 96:

$673633-665$.

674 Olson, E. C. 1944. Origin of mammals based upon cranial morphology of the therapsid

675 suborders. Geological Society of America, Special Papers 55: 1-136.

676 Olson, E. C. 1962. Late Permian terrestrial vertebrates, USA and USSR. Transactions of the

677 American Philosophical Society, new series 52: 1-224.

678 O’Shea, T. J. and Reep R. L. 1990. Encephalization Quotients and Life-History Traits in the

679 Sirenia. Journal of Mammalogy 71: 534-543. 
680 Paganin, D., Mayo, S.C., Gureyev, T.E., Miller, P.R. and Wilkins, S.W. 2002. Simultaneous

681 phase and amplitude extraction from a single defocused image of a homogeneous object. Journal 682 of Microscopy 6: 33-40.

683 Pérez-Barbería, F. J. and Gordon, I. J. 2005. Gregariousness increases brain size in ungulates. 684 Oecologia 145: 41-52.

685 Quay, W. B. 1979. The parietal eye-pineal complex. Pp. 245-406 in C. Gans, R.G. Northcutt, 686 and P. Ulinski eds. Biology of the Reptilia, Vol. 9. Academic Press, New York.

687 Quiroga, J. C. 1980. The brain of the mammal-like reptile Probainognathus jenseni (Therapsida, 688 Cynodontia). A correlative paleo-neoneurological approach to the neocortex at the reptile689 mammal transition. The Journal für Hirnforschung 21: 299-336.

690 Quiroga, J. C. 1984. The endocranial cast of the advanced mammal-like reptile Therioherpeton 691 cargnini (Therapsida-Cynodontia) from the Middle Triassic of Brazil. The Journal für 692 Hirnforschung 25: 285-290.

693 Rodrigues, P. G., Ruf, I. and Schultz, C. L. 2013a. Study of a digital cranial endocast of the non694 mammaliaform cynodont Brasilitherium riograndensis (Later Triassic, Brazil) and its relevance 695 to the evolution of the mammalian brain. Paläontologische Zeitschrift 88: 329-352.

696 Rodrigues, P. G., Ruf, I. and Schultz, C. L. (2013b) Digital Reconstruction of the Otic Region 697 and Inner Ear of the Non-Mammalian Cynodont Brasilitherium riograndensis (Late Triassic, 698 Brazil) and Its Relevance to the Evolution of the Mammalian Ear. Journal of Mammalian 699 Evolution 20: 291-307.

700 Rowe, T. B., Macrini, T. E. and Luo, Z.-X. 2011. Fossil evidence on origin of the mammalian 701 brain. Science 332: 955-957. 
702 Roth, J. J., Roth, E. C. and Hotton, N. N. 1986. The parietal foramen and eye: their function and 703 fate in therapsids. Pp. 173-184 in N. Hotton, P. D. MacLean, J. J. Roth, and E. D. Roth, eds.

704 Ecology and Biology of Mammal-like Reptiles. Smithsonian Institution Press, Washington D. C.

705 Rubidge, B. S. and Sidor, C. A. 2001. Evolutionary patterns among Permo-Triassic Therapsids.

706 Annual Review of Ecology, Evolution, and Systematics 32: 449-480.

707 Seeley, H. G. 1894. Researches on the Structure, Organisation, and Classification of the Fossil

708 Reptilia. Part IX., Section 1. On the Therosuchia. Philosophical Transactions of the Royal

709 Society Series B: Biological Sciences 185: 987-1018.

710 Sereno, P. C., Wilson J. A., Witmer L. M., Whitlock J. A., Maga A., Ide O. and Rowe T. A.

711 2007. Structural extremes in a Cretaceous dinosaur. PLoS ONE 2: e1230.

712 Sigogneau, D. 1970. Revision systematique des gorgonopsiens Sud-Africains. Cahiers de 713 Paleontologie, Paris.

714 Sigogneau, D. 1974. The Inner ear of Gorgonops (Reptilia, Therapsida, Gorgonopsia). Annals of 715 the South African Museum 64: 53-69.

716 Sigurdsen, T., Huttenlocker, A., Modesto, S.P., Rowe, T.B. and Damiani, R. 2012. Reassessment

717 of the Morphology and Paleobiology of the Therocephalian Tetracynodon darti (Therapsida),

718 And The Phylogenetic Relationships of Baurioidea. Journal of Vertebrate Paleontology 32:

$719 \quad 1113-1134$.

720 Solounias, N. 2007. Family Bovidae. Pp. 278-291, in D. R. Prothero, S. E. Foss, eds. The

721 Evolution of Artiodactyls. University of The Johns Hopkins Press, Baltimore. 
722 Sookias, R. B., Butler, R. J. and Benson, B. J. 2012. Rise of dinosaurs reveals major body-size

723 transitions are driven by passive processes. Proceedings of the Royal Society B: Biological

724 Sciences 279: 2180-2187.

725 Sues, H. D. 1978 Functional morphology of the dome in pachycephalosaurid dinosaurs. Neues

726 Jahrbuch für Geologie und Paläontologie 1978: 459-472.

727 Vidal P. P., Graf W. and Berthoz A. 1986 The orientation of the cervical vertebral column in

728 unrestrained awake animals. I. Resting position. Experimental Brain Research 61:549-559.

729 Walsh, S. A., Luo, Z.-X. and Barrett, P. M. 2013. Modern imaging techniques as a window to 730 prehistoric auditory worlds. Pp. 227-261, in C. Köppl, ed. Insights from comparative hearing 731 research. Springer, New York.

732 Witmer, L. M., Chatterjee, S., Franzosa, J. and Rowe, T. 2003. Neuroanatomy of flying reptiles 733 and implications for flight, posture and behaviour. Nature 425: 950-953.

734 Witmer, L. M., Ridgely, R. C., Dufeau, D. L. and Semones, M. C. 2008. Using CT to peer into 735 the past: 3D visualisation of the brain and ear regions of birds, crocodiles and nonavian 736 dinosaurs. Pp. 67-87, in H. Endo and R. Frey, eds. Anatomical imaging: Towards a new 737 morphology. Springer-Verlag, Tokyo.

\section{$738 \quad$ Figure legends}

Figure 1. The skull of Moschops capensis AM4950 in lateral view. A, photograph of the skull.

$740 \mathrm{~B}$, reconstruction of the skull (right side, bone transparent) to reveal the neural structures

741 discussed in this paper. C, reconstruction of the skull (left side, bone transparent) showing the

742 endocast, bony labyrinth and the angle between the plane of the lateral semicircular canal and the 743 main axis of the skull. Numbers indicate the position of the cross sections in the subsequent 
744 figures. EmV, emissary veins; End, endocranial cast; Hyp, hypophyseal fossa; Lab, bony

745 labyrinths; Pin, pineal tube. Photo by LN.

746 Figure 2. CT sections of the skull of Moschops capensis AM4950 in positions 1 and 2 (see Fig.

747 1B). Abbreviations: Bas, basisphenoid; BrC, braincase; Floc, floccular fossa; FMg, foramen

748 magnum; Hyp, hypophyseal fossa; Mes, mesethmoid; FPS, fronto-parietal shield; Fr, frontal

749 bone; Lab, bony labyrinth; Orbsp, orbitosphenoid; PostFr, postfrontal bone; PostOrb, postorbital

750 bone; PrOt, prootic.

751 Figure 3. Digital reconstruction of the brain endocast and bony labyrinth of Moschops capensis

752 AM4950 digitally reconstructed. A-C, Endocranial cast in lateral (left and right) and dorsal

753 views (pineal tube removed in C for clarity); D, Bony labyrinth in lateral, posterior and dorsal

754 views.Abbreviations: I, olfactory tract; II, optic nerve; V, trigeminal nerve; VII, facial nerve;

755 VIII, vestibulo-cochlear nerve; XI, accessory nerve; XII, hypoglossal nerve; AntAMp, anterior

756 ampulla; ASC, anterior semicircular canal; CC, common crus; CCII, secondary common crus;

757 FMg, foramen magnum; Floc, floccular fossa; Hyp, hypophyseal fossa; IntCar, internal carotid

758 artery; JugF, jugular foramen; Lab, bony labyrinth; LatAmp, lateral ampulla; LSC, lateral

759 (horizontal) semicircular canal; Mcv, middle cerebral vein; ParF, parietal foramen; PinT, pineal

760 tube; PSC, posterior semicircular canal; Vest, vestibule; Fvest, fenestra vestibuli.

761 Figure 4. Digital reconstruction of the trigeminal canals, presumably for branches of the

762 trigeminal nerve, of Moschops capensis AM4950. Abbreviations: CaudA1, caudal alveolar ramus

763 of the maxillary canal; ExtNas, external nasal ramus of the maxillary canal; IntNas, internal nasal

764 ramus of the maxillary canal; Mand, mandibular ramus; MedAl, medium alveolar ramus of the

765 maxillary canal; MxAnt, maxillary antrum; OphFr, frontal ramus of the ophthalmic branch; 
766 OphNas, nasal ramus of the ophthalmic branch; RostAl, rostral alveolar ramus of the maxillary

767 canal; SupLab, superior labial ramus of the maxillary canal.

768 Figure 5. Hypothesized reconstructions of the natural head posture in Moschops capensis. A,

769 Redrawn after the mounted skeleton at the American Museum of Natural History (Gregory,

770 1926). B, Based on the position of the plane of the lateral (horizontal) canal. Artwork by JB.

771 Figure 6. Hypothesized dissipation of the energy during head butting in the skull of Moschops

772 capensis based on the morphological arrangement of the bones in the braincase. Arrows indicate

773 the hypothesized direction of energy transfer through the thickest bones. A, CT section of the

774 skull of Moschops capensis AM4950 in position 3 (see Fig. 1B). B, The proposed route of the

775 dissipation of energy through the dermatocranium (left) and the braincase (right) in two fighting

776 Moschops. Abbreviations: Bas, basicranium; BrC, braincase; CR, cranial roof; Ept, epipterygoid;

777 FMg, foramen magnum; FPS, fronto-parietal shield; Occ, occipital condyles; PrOt; prootic.

778 Artworks by JB.

779 Figure 7. Comparison of the orientation of the braincase (white) and the skull (black) in

780 Moschops and Stegoceras. A, comparison of the pontine flexure (indicated by the arrow) in

781 Moschops and its absence in the pachycephalosaurid Stegoceras (redrawn after Bourke et al.,

782 2014). B, the skull of Moschops and Stegoceras (redrawn after Bourke et al., 2014) aligned

783 according to the plan of their lateral semicircular canals.

784 Figure 8. Orientation of the braincase (white) compared to that of the skull (black) in

785 Therapsida. 1, redrawn after Boonstra (1968); 2, redrawn after Laaß, 2015; 3, redrawn after

786 Lehman, 1961; 4, Castanhinha et al., 2013; 5, Araujo et al., 2016 ; 6, Sigurdsen et al., 2012 ; 7 ,

787 Rodrigues et al., 2013a; 8, Kemp, 2009. 


\section{Table $\mathbf{1}$ (on next page)}

Measurements of the endocranial cast and calculations of body mass and encehalization quotients in Therapsida.

Abbreviations: BM, body mass; EQ, encephalization quotient; EV, endocast volume. 
1 Table 1. Measurements of the endocranial cast and calculations of body mass and encehalization

2 quotients in Therapsida. Abbreviations: BM, body mass; EQ, encephalization quotient; EV,

3 endocast volume. * indicates taxa for which BM was recalculated (see material and methods)

$4 \quad$ Raw data $]$

5

6

\begin{tabular}{|c|c|c|c|c|c|c|}
\hline & & $\begin{array}{l}\text { Skull } \\
\text { length } \\
(\mathrm{mm})\end{array}$ & $\mathrm{BM} 1(\mathrm{~g})$ & $\mathrm{BM} 2(\mathrm{~g})$ & $\mathrm{BM} 3(\mathrm{~g})$ & $\begin{array}{l}\text { Average } \\
\text { BM (g) }\end{array}$ \\
\hline Moschops & Dinocephalia & 340 & 106299 & 215918 & 63748 & 128655 \\
\hline Moschops (no pineal tube) & Dinocephalia & - & - & - & - & 128655 \\
\hline Moschops (Jerison 1973's BM) & Dinocephalia & - & - & - & - & 327367 \\
\hline Moschops (Bakker 1975's BM) & Dinocephalia & - & - & - & - & 700000 \\
\hline $\begin{array}{l}\text { Strutiocephalus } \\
\text { Strutiocephalus (Bakker 1975's }\end{array}$ & Dinocephalia & 443 & 234686 & 493346 & 136495 & 288176 \\
\hline BM) & Dinocephalia & - & - & - & - & 1000000 \\
\hline Pristerodon & Dicynodontia & - & - & - & - & 1358 \\
\hline Pristerodon* & Dicynodontia & 78 & 1281 & 2149 & 1012 & 1481 \\
\hline Niassodon & Dicynodontia & - & - & - & - & 491 \\
\hline Niassodon* & Dicynodontia & 63 & 675 & 1101 & 570 & 782 \\
\hline Lystrosaurus & Dicynodontia & 180 & 15746 & 29444 & 10342 & 18511 \\
\hline Tetracynodon & Therocephalia & 75 & 1139 & 1901 & 910 & 1317 \\
\hline Brasilitherium & Cynodontia & - & - & - & - & 99 \\
\hline Brasilitherium* & Cynodontia & 38 & 149 & 227 & 154 & 176 \\
\hline Therioherpeton & Cynodontia & - & - & - & - & 64 \\
\hline Therioherpeton* & Cynodontia & 31 & 80 & 120 & 93 & 98 \\
\hline Probainognathus & Cynodontia & - & - & - & - & 590 \\
\hline Probainognathus* & Cynodontia & 65 & 741 & 1215 & 619 & 858 \\
\hline cf. Probelesodon & Cynodontia & - & - & - & - & 3807 \\
\hline cf. Probelesodon* & Cynodontia & 120 & 4666 & 8276 & 3310 & 5417 \\
\hline Exaeretodon & Cynodontia & - & - & - & - & 46877 \\
\hline Exaeretodon* & Cynodontia & 278 & 58009 & 114778 & 35699 & 69496 \\
\hline Massetognathus & Cynodontia & - & - & - & - & 1865 \\
\hline Massetognathus* & Cynodontia & 95 & 2315 & 3984 & 1734 & 2677 \\
\hline Diademodon & Cynodontia & - & - & - & - & 50000 \\
\hline
\end{tabular}




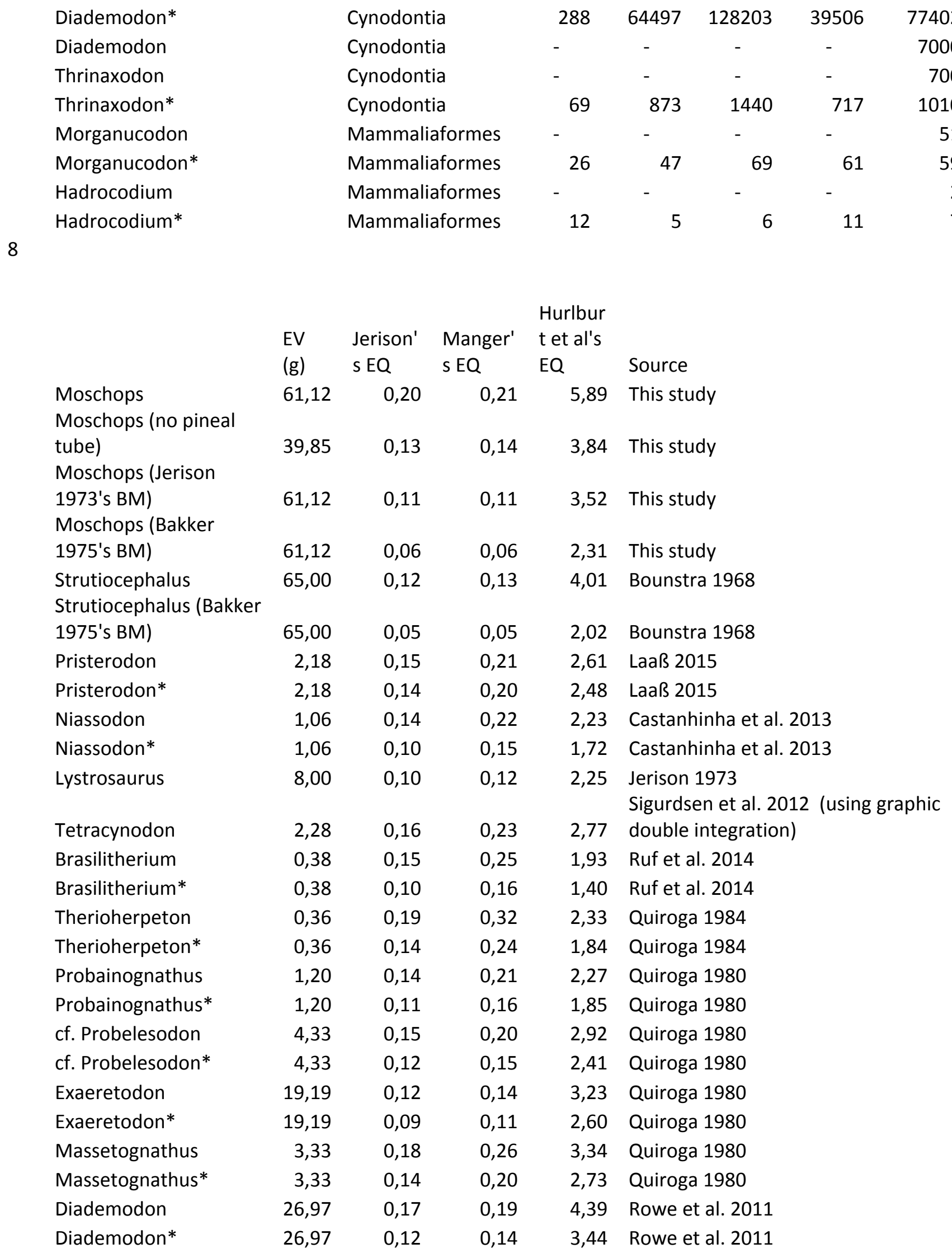




$\begin{array}{llllll}\text { Diademodon } & 8,00 & 0,18 & 0,23 & 3,86 & \text { Jerison 1973 } \\ \text { Thrinaxodon } & 1,46 & 0,15 & 0,23 & 2,52 & \text { Rowe et al. 2011 } \\ \text { Thrinaxodon* } & 1,46 & 0,12 & 0,18 & 2,06 & \text { Rowe et al. 2011 } \\ \text { Morganucodon } & 0,33 & 0,20 & 0,35 & 2,38 & \text { Rowe et al. 2011 } \\ \text { Morganucodon* } & 0,33 & 0,18 & 0,31 & 2,20 & \text { Rowe et al. 2011 } \\ \text { Hadrocodium } & 0,05 & 0,24 & 0,51 & 1,99 & \text { Rowe et al. 2011 } \\ \text { Hadrocodium* } & 0,05 & 0,10 & 0,20 & 0,96 & \text { Rowe et al. 2011 }\end{array}$




\section{Figure 1}

The skull of Moschops capensis AM4950 in lateral view.

A, photograph of the skull. $B$, reconstruction of the skull (right side, bone transparent) to reveal the neural structures discussed in this paper. C, reconstruction of the skull (left side, bone transparent) showing the endocast, bony labyrinth and the angle between the plane of the lateral semicircular canal and the main axis of the skull. Numbers indicate the position of the cross sections in the subsequent figures. EmV, emissary veins; End, endocranial cast; Hyp, hypophyseal fossa; Lab, bony labyrinths; Pin, pineal tube. Photo by LN.
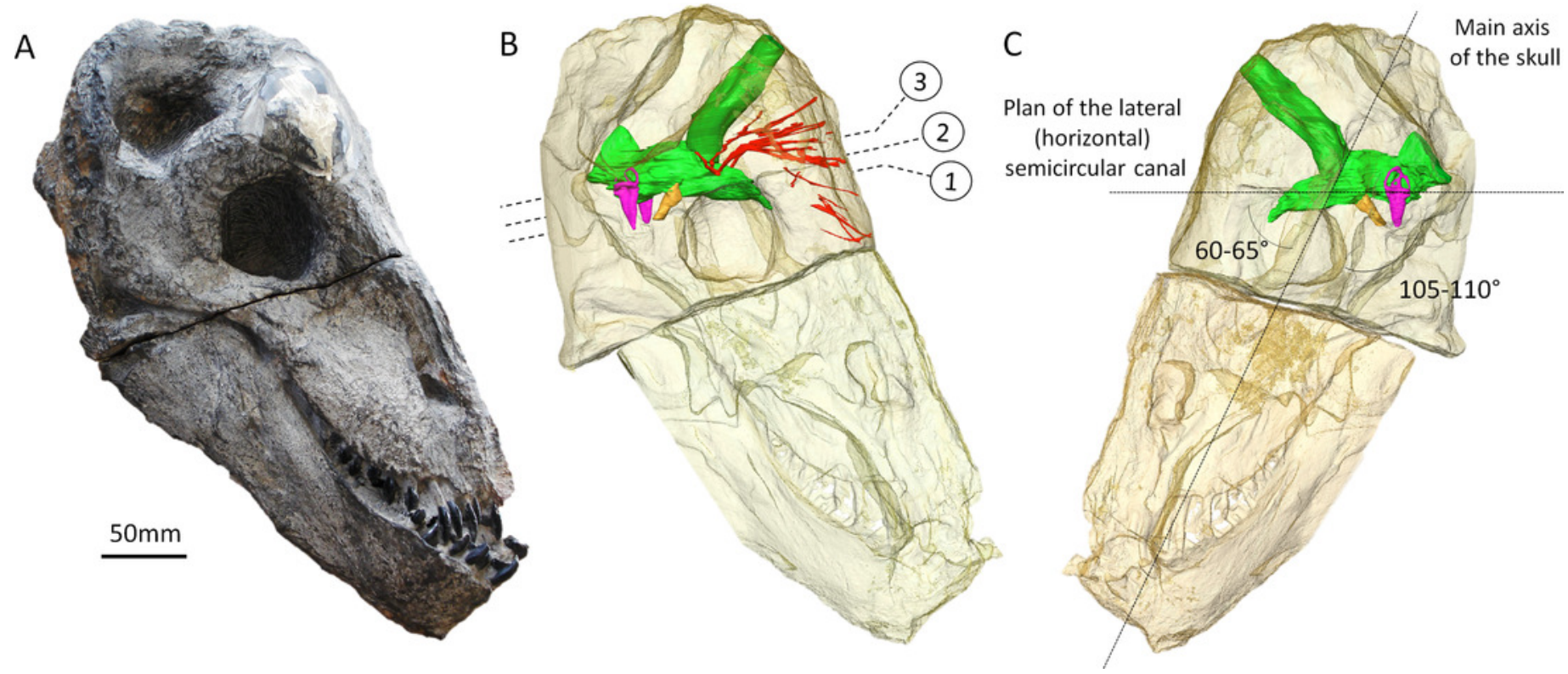


\section{Figure 2}

CT sections of the skull of Moschops capensis AM4950 in positions 1 and 2 (see Fig. 1B).

Abbreviations: Bas, basisphenoid; BrC, braincase; Floc, floccular fossa; FMg, foramen magnum; Hyp, hypophyseal fossa; Mes, mesethmoid; FPS, fronto-parietal shield; Fr, frontal bone; Lab, bony labyrinth; Orbsp, orbitosphenoid; PostFr, postfrontal bone; PostOrb, postorbital bone; PrOt, prootic.

*Note: Auto Gamma Correction was used for the image. This only affects the reviewing manuscript. See original source image if needed for review.

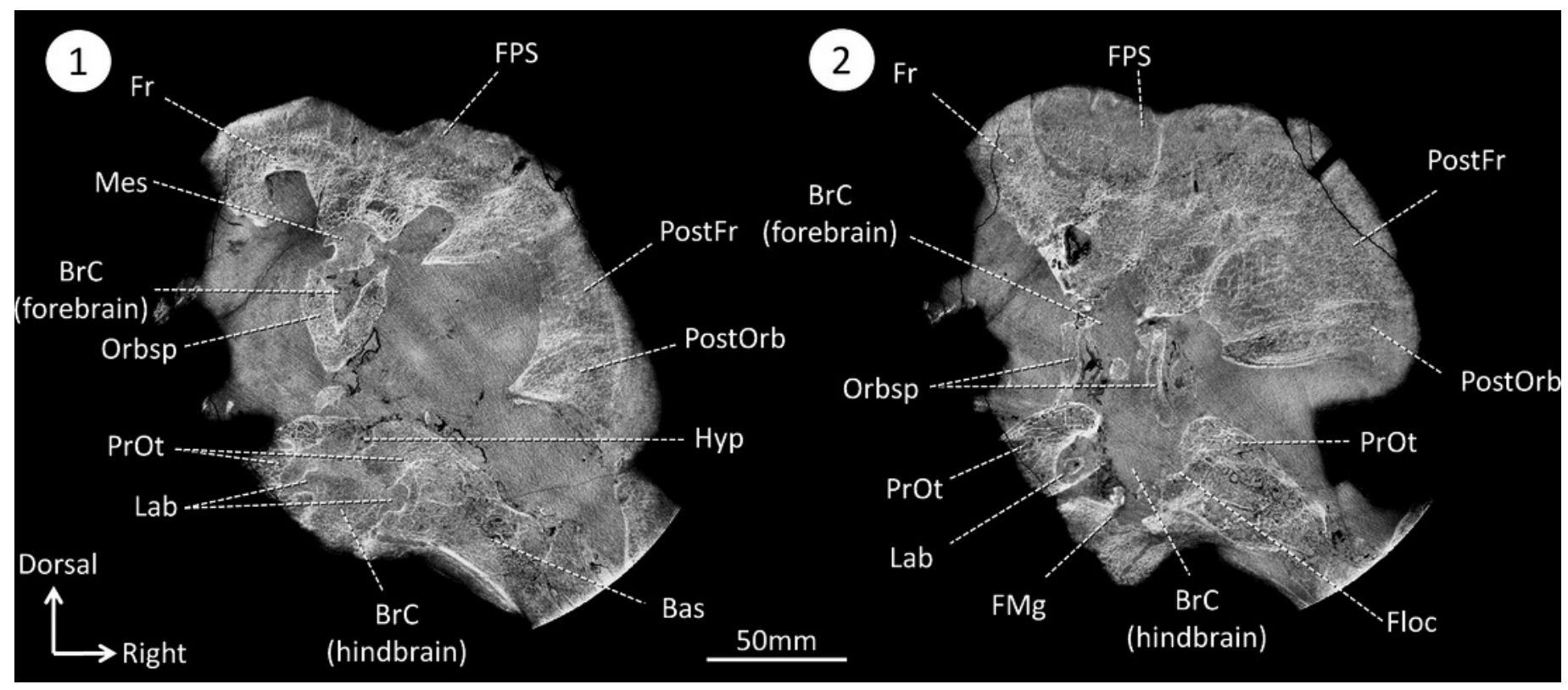




\section{Figure 3}

Digital reconstruction of the brain endocast and bony labyrinth of Moschops capensis AM4950 digitally reconstructed.

A-C, Endocranial cast in lateral (left and right) and dorsal views (pineal tube removed in C for clarity); D, Bony labyrinth in lateral, posterior and dorsal views.Abbreviations: I, olfactory tract; II, optic nerve; V, trigeminal nerve; VII, facial nerve; VIII, vestibulo-cochlear nerve; XI, accessory nerve; XII, hypoglossal nerve; AntAMp, anterior ampulla; ASC, anterior semicircular canal; CC, common crus; CCII, secondary common crus; FMg, foramen magnum; Floc, floccular fossa; Hyp, hypophyseal fossa; IntCar, internal carotid artery; JugF, jugular foramen; Lab, bony labyrinth; LatAmp, lateral ampulla; LSC, lateral (horizontal) semicircular canal; Mcv, middle cerebral vein; ParF, parietal foramen; PinT, pineal tube; PSC, posterior semicircular canal; Vest, vestibule; Fvest, fenestra vestibuli. 

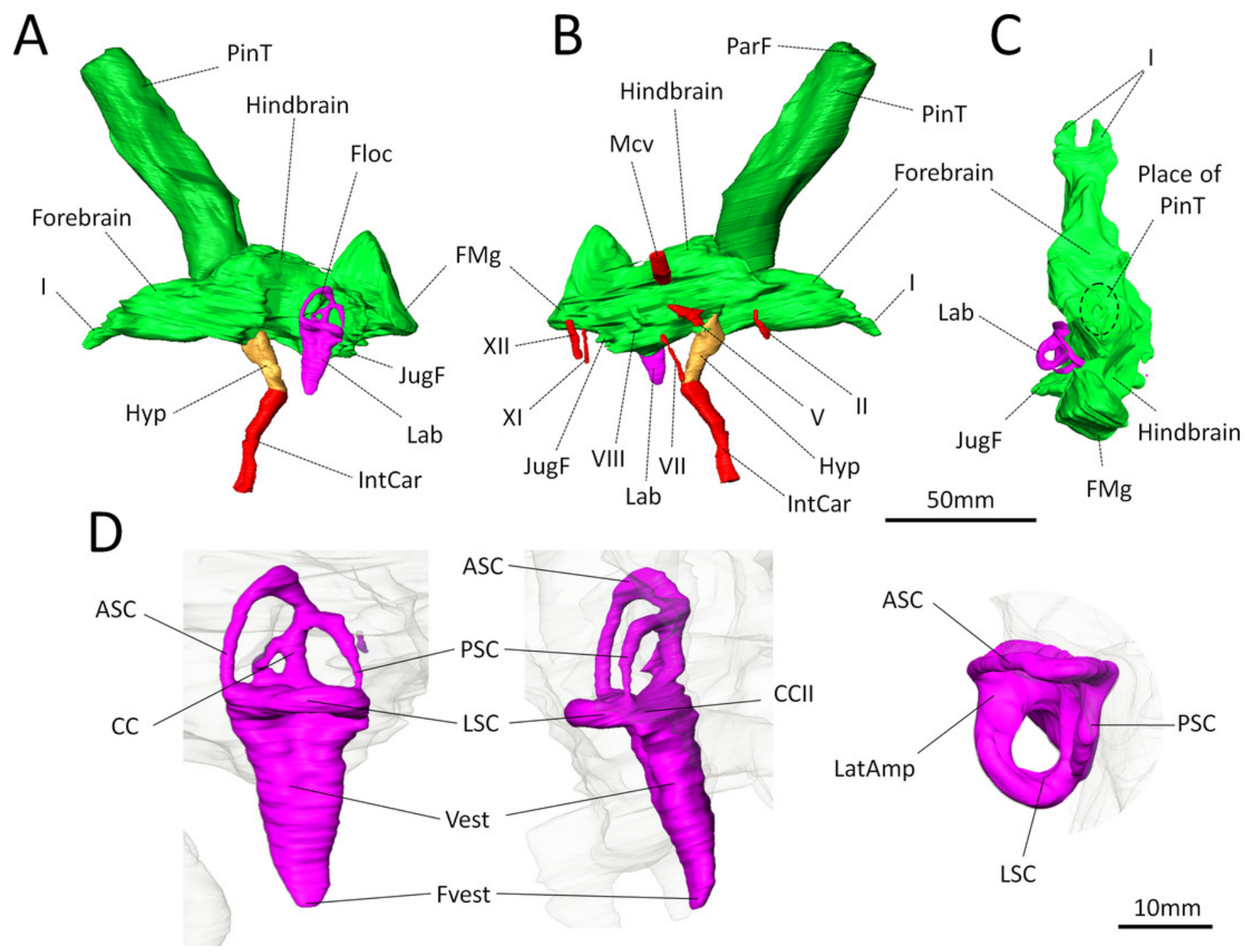

$10 \mathrm{~mm}$ 


\section{Figure 4}

Digital reconstruction of the trigeminal canals, presumably for branches of the trigeminal nerve, of Moschops capensis AM4950.

Abbreviations: CaudAl, caudal alveolar ramus of the maxillary canal; ExtNas, external nasal ramus of the maxillary canal; IntNas, internal nasal ramus of the maxillary canal; Mand, mandibular ramus; MedAl, medium alveolar ramus of the maxillary canal; MxAnt, maxillary antrum; OphFr, frontal ramus of the ophthalmic branch; OphNas, nasal ramus of the ophthalmic branch; RostAl, rostral alveolar ramus of the maxillary canal; SupLab, superior labial ramus of the maxillary canal.

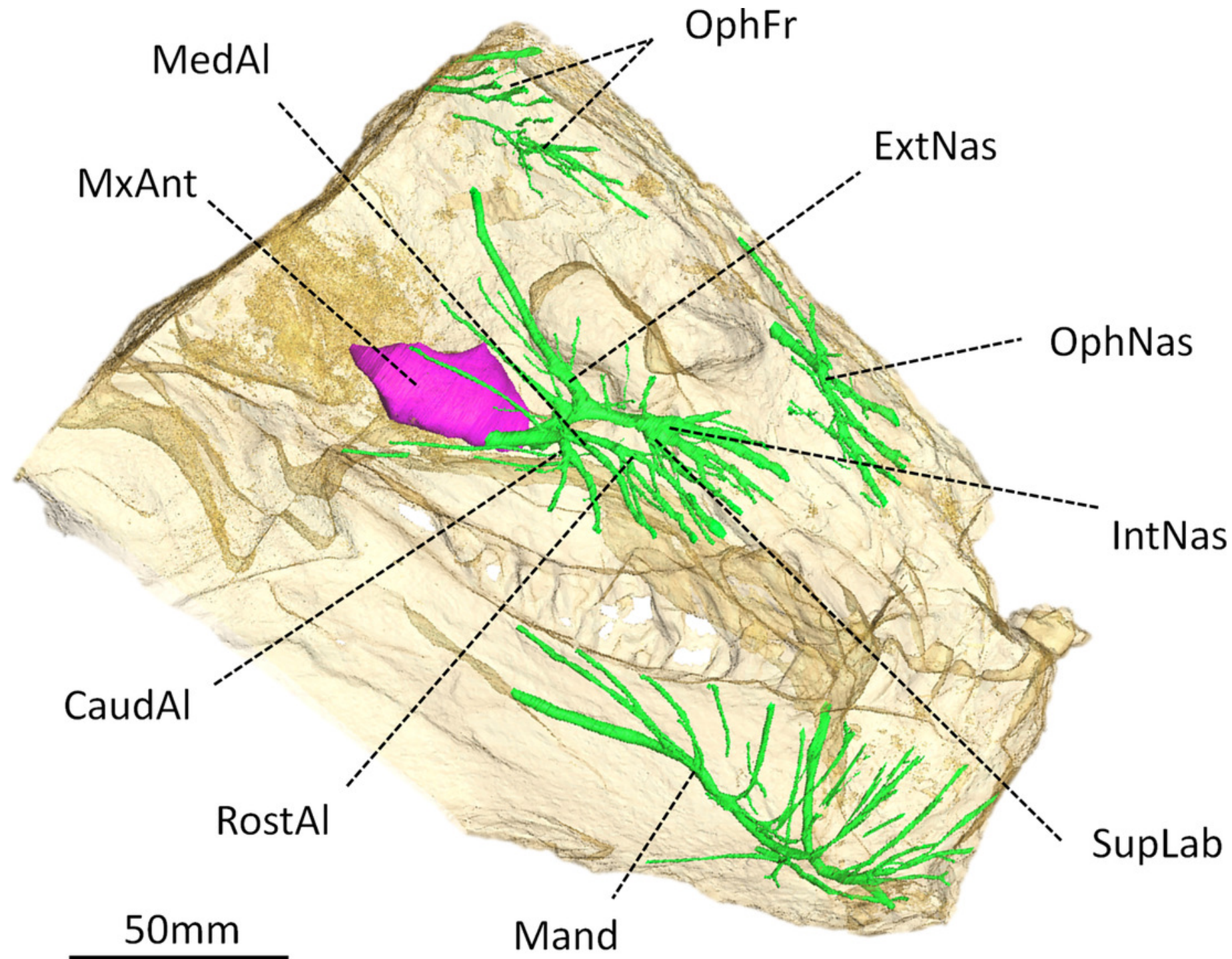


Figure 5

Hypothesized reconstructions of the natural head posture in Moschops capensis.

A, Redrawn after the mounted skeleton at the American Museum of Natural History (Gregory, 1926). B, Based on the position of the plane of the lateral (horizontal) canal. Artwork by JB.

A

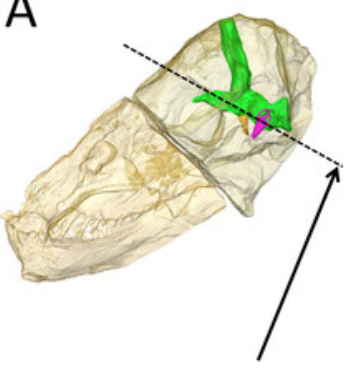

Plan of the lateral semicircular canal

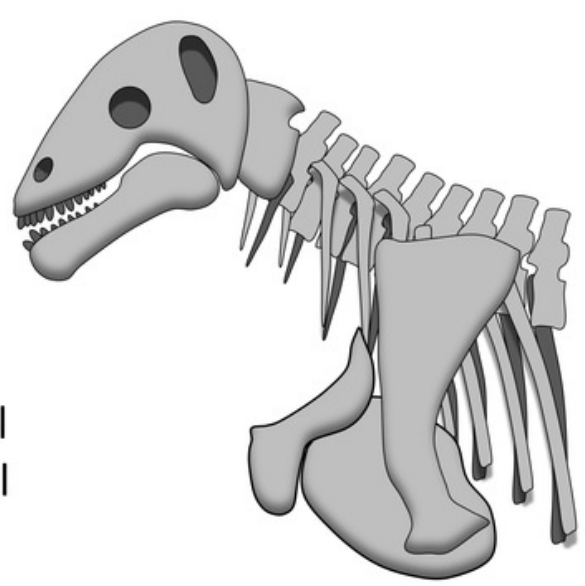

B

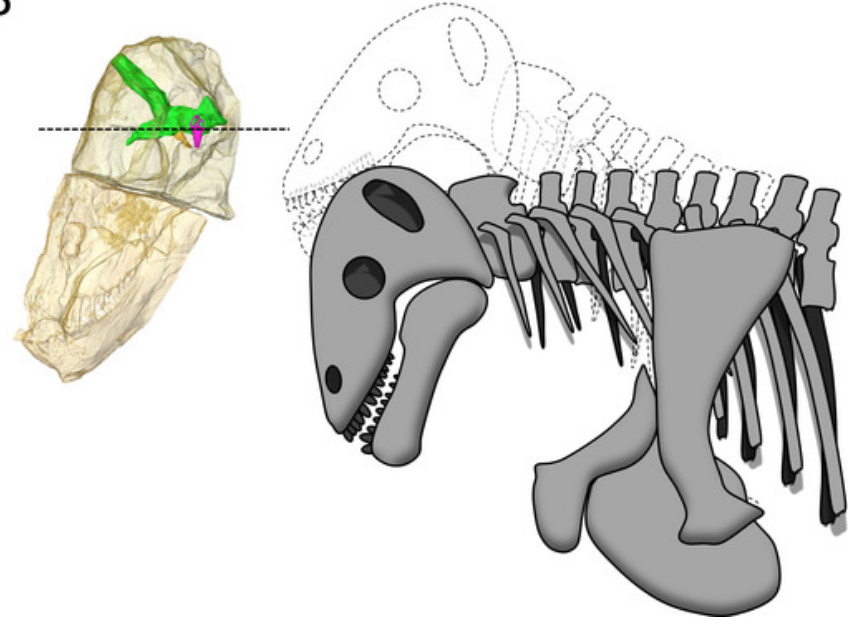




\section{Figure 6}

Hypothesized dissipation of the energy during head butting in the skull of Moschops capensis.

Arrows indicate the direction of energy transfer. A, CT section of the skull of Moschops capensis AM4950 in position 3 (see Fig. 1B). B, The proposed route of the dissipation of energy through the dermatocranium (left) and the braincase (right) in two fighting Moschops. Abbreviations: Bas, basicranium; BrC, braincase; CR, cranial roof; Ept, epipterygoid; FMg, foramen magnum; FPS, fronto-parietal shield; Occ, occipital condyles; PrOt; prootic. Artworks by JB. 

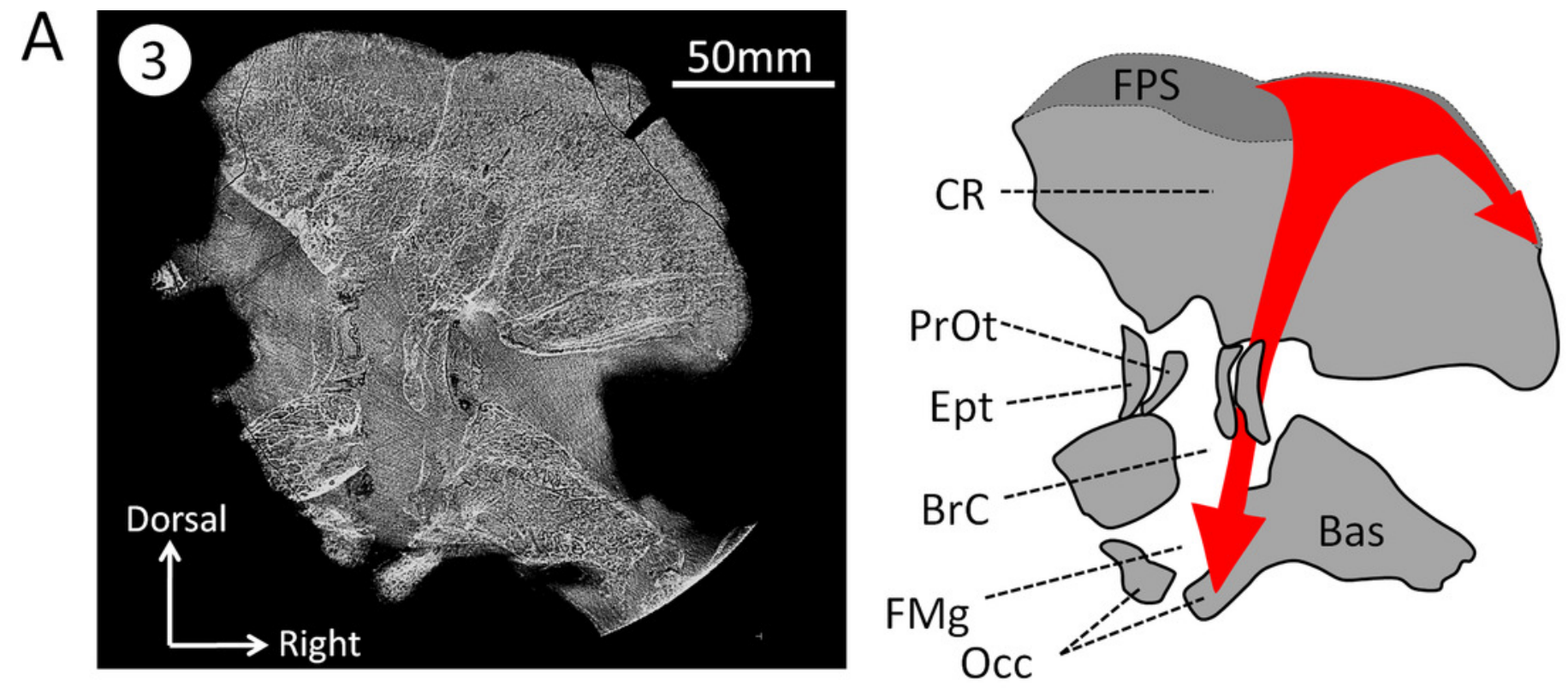

B

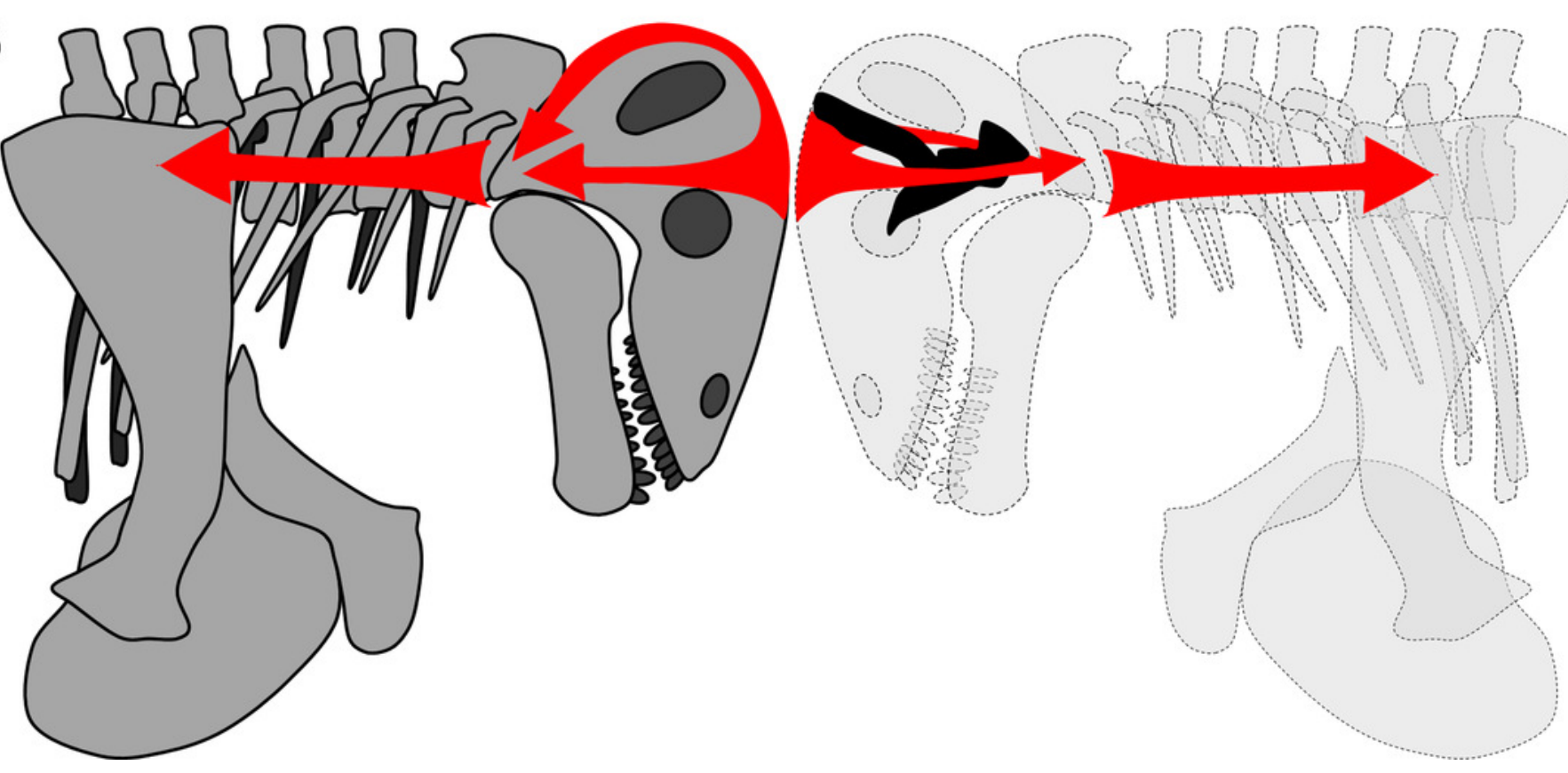




\section{Figure 7}

Comparison of the orientation of the braincase (white) and the skull (black) in Moschops and Stegoceras.

A, comparison of the pontine flexure (indicated by the arrow) in Moschops and its absence in the pachycephalosaurid Stegoceras (redrawn after Bourke et al., 2014). B, the skull of Moschops and Stegoceras (redrawn after Bourke et al., 2014) aligned according to the plan of their lateral semicircular canals. 
A
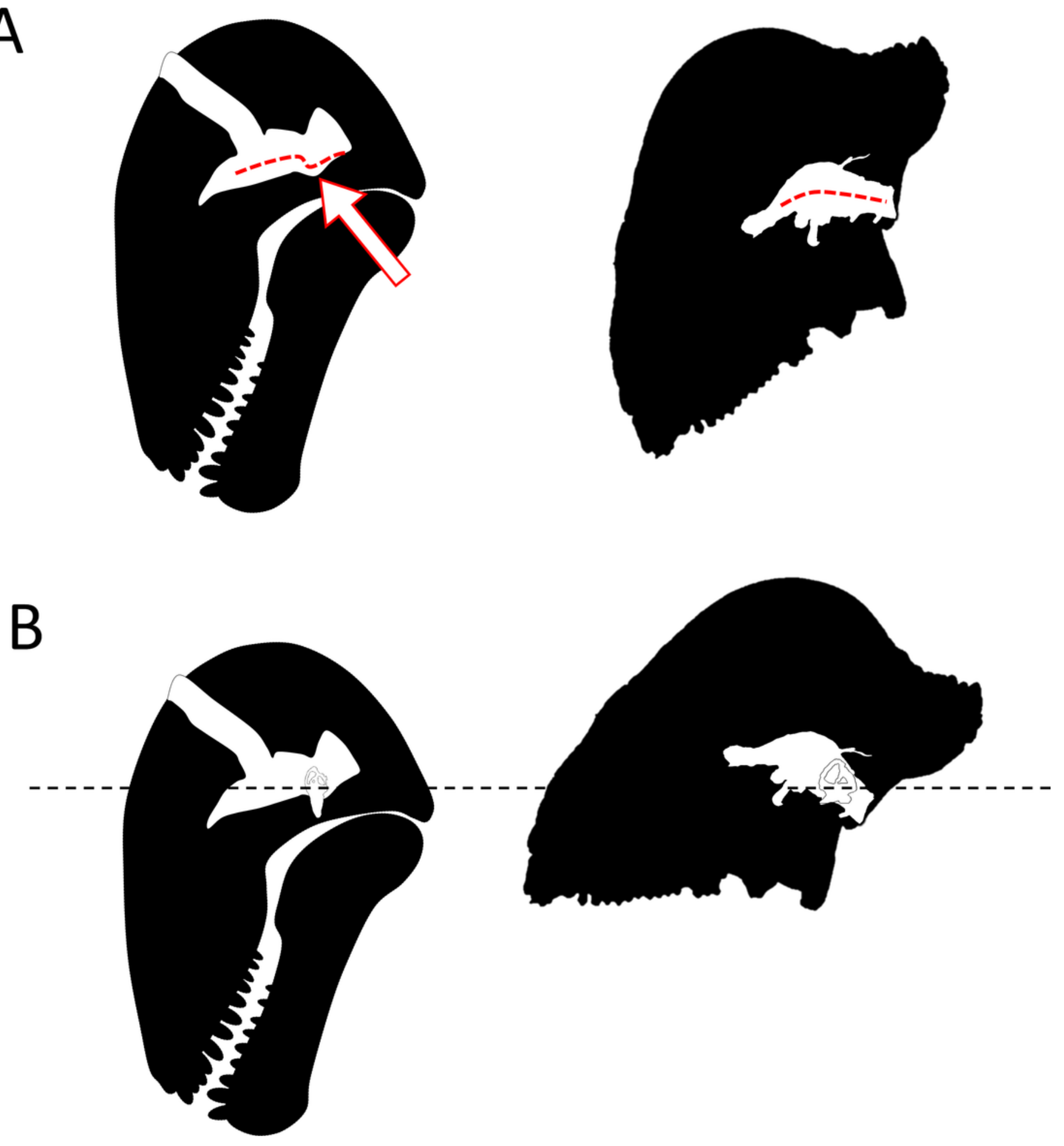


\section{Figure 8}

Orientation of the braincase (white) compared to that of the skull (black) in Therapsida.

1, redrawn after Boonstra (1968); 2, redrawn after Laaß, 2015; 3, redrawn after Lehman, 1961; 4, Castanhinha et al., 2013; 5, Araujo et al., 2016; 6, Sigurdsen et al., 2012; 7 , Rodrigues et al., 2013a; 8, Kemp, 2009.

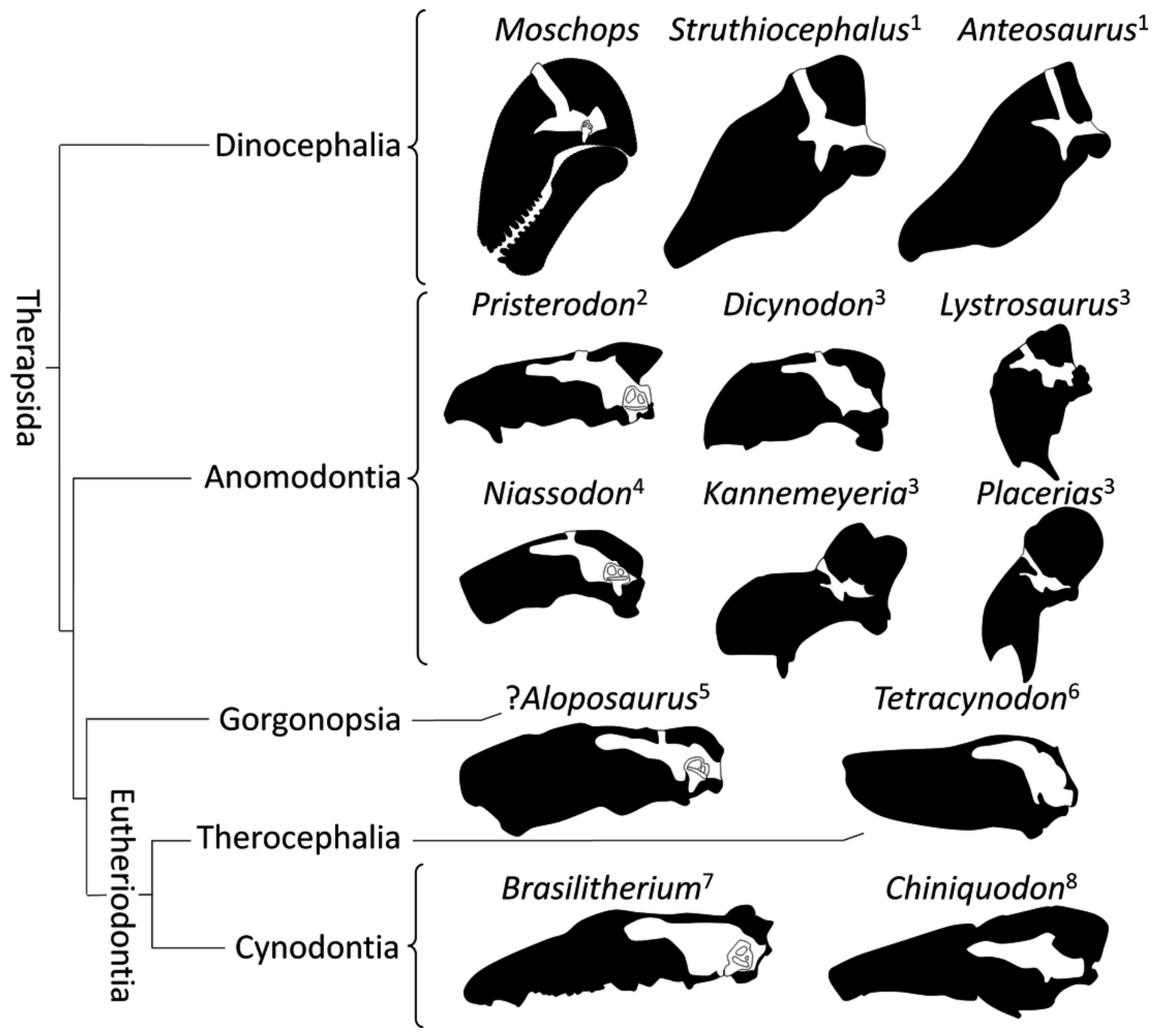

